\title{
Disruption of IRE1 $\alpha$ through its Kinase Domain Attenuates Multiple Myeloma
}

Jonathan M Harnoss ${ }^{\mathrm{a}}$, Adrien Le Thomas ${ }^{\mathrm{a}}$, Scot A Marsters ${ }^{\mathrm{a}}$, David A Lawrence ${ }^{\mathrm{a}}$, Min Lu ${ }^{\mathrm{a}, 1}$, Yung-Chia Ariel Chen ${ }^{\mathrm{a}}$, Jing Qing ${ }^{\mathrm{a}}$, Klara Totpal ${ }^{\mathrm{b}}$, David Kan ${ }^{\mathrm{b}}$, Ehud Segal ${ }^{\mathrm{b}}$, Heidi Ackerly

Wallweber ${ }^{\mathrm{c}}$, Weiru Wang ${ }^{\mathrm{c}}$, Kevin Clark ${ }^{\mathrm{d}}$, Susan Kaufman ${ }^{\mathrm{d}}$, Maureen Beresini ${ }^{\mathrm{d}}$, Wendy Sandoval $^{\mathrm{e}}$, Maria Lorenzo ${ }^{\mathrm{f}}$, Jiansheng Wu ${ }^{\mathrm{f}}$, Justin Ly ${ }^{\mathrm{g}}$, Tom De Bruyn ${ }^{\mathrm{g}}$, Amy Heidersbach ${ }^{\mathrm{h}}$, Benjamin Haley ${ }^{\mathrm{h}}$, Alvin Gogineni ${ }^{\mathrm{i}}$, Robby Weimer ${ }^{\mathrm{i}}$, Dong Lee ${ }^{\mathrm{j}, 2}$, Marie-Gabrielle Braun ${ }^{\mathrm{k}}$, Joachim Rudolph $^{\mathrm{k}}$, Michael J VanWyngarden ${ }^{1}$, Daniel W Sherbenou ${ }^{1}$, Patricia Gomez-Bougie ${ }^{\mathrm{m}, \mathrm{n}}$, Martine Amiot ${ }^{\mathrm{m}, \mathrm{n}}$, Diego Acosta-Alvear ${ }^{\mathrm{o}, \mathrm{p}, 3}$, Peter Walter $^{\mathrm{o}, \mathrm{p}}$ and Avi Ashkenazi ${ }^{\mathrm{a}, 4}$

${ }^{a}$ Cancer Immunology, Genentech, Inc., 1 DNA Way, South San Francisco, CA 94080 USA. ${ }^{\mathrm{b} T r a n s l a t i o n a l}$ Oncology, 1 DNA Way, South San Francisco, CA 94080 USA. 'Structural Biology, 1 DNA Way, South San Francisco, CA 94080 USA. ${ }^{d}$ Biochemical and Cellular Pharmacology, Genentech, Inc. 1 DNA Way, South San Francisco, CA 94080 USA. ${ }^{e}$ Microchemistry, Proteomics and Lipidomics, Genentech, Inc. 1 DNA Way, South San Francisco, CA 94080 USA. Protein Chemistry, Genentech, Inc. 1 DNA Way, South San Francisco, CA 94080 USA. gDrug Metabolism and Pharmacokinetics, Genentech, Inc. 1 DNA Way, South San Francisco, CA 94080 USA. holecular Biology, Genentech, Inc. 1 DNA Way, South San Francisco, CA 94080 USA. 'Biomolecular Imaging, Genentech, Inc. 1 DNA Way, South San Francisco, CA 94080 USA. jSafety Assessment, Genentech, Inc. 1 DNA Way, South San Francisco, CA 94080 USA. 'Discovery Chemistry, Genentech, Inc. 1 DNA Way, South San Francisco, CA 94080 USA. 'Division of Hematology, Department of Medicine, University of Colorado Cancer Center, University of Colorado Anschutz Medical Campus, Aurora CO 80045 USA. ${ }^{\mathrm{m} C R C I N A}$, INSERM, CNRS, Université d'Angers, Université de Nantes, Nantes, BP 70721, France. " Service d'Hématologie Clinique, Unité d'Investigation Clinique, CHU, Nantes, BP 70721 France. ${ }^{\circ}$ Department of Biochemistry and Biophysics, University of California San Francisco, San Francisco, CA 94143 USA. ${ }^{p}$ Howard Hughes Medical Institute, University of California San Francisco, San Francisco, CA 94143 USA. ${ }^{1}$ Current address: Agios Pharmaceuticals, 88 Sidney Street, Cambridge, MA 02139 USA. ${ }^{2}$ Current address: Revolution Medicines, 700 Saginaw Dr., Redwood City, CA 94063. ${ }^{3}$ Current address: Department of Molecular, Cellular and Developmental Biology, University of California Santa Barbara, Santa Barbara, CA 93106 USA. ${ }^{4}$ Corresponding author: Tel: +1 650-225-1853, email: aa@gene.com

\section{Classification: Biological Sciences, Cell Biology}

Short title: IRE1 kinase disruption attenuates multiple myeloma

Key words: Multiple myeloma, endoplasmic reticulum stress, unfolded protein response, inositol requiring enzyme 1 , kinase inhibitors 


\begin{abstract}
Multiple myeloma (MM) arises from malignant immunoglobulin-secreting plasma cells and remains an incurable, often lethal disease despite recent therapeutic advances. The unfoldedprotein response sensor IRE1 $\alpha$ supports protein secretion by deploying a kinaseendoribonuclease module to activate the transcription factor XBP1s. MM cells may coopt the IRE1 $\alpha$-XBP1s pathway; however, the validity of IRE1 $\alpha$ as a potential MM therapeutic target is controversial. Here we show that genetic disruption of IRE1 $\alpha$ or XBP1s, or pharmacologic IRE1 $\alpha$ kinase inhibition, attenuated subcutaneous or orthometastatic growth of MM tumors in mice, and augmented efficacy of two well-established frontline antimyeloma agents, bortezomib or lenalidomide. Mechanistically, IRE1 $\alpha$ perturbation inhibited expression of key components of the ER-associated degradation machinery, as well as cytokines and chemokines known to promote MM growth. Selective IRE1 $\alpha$ kinase inhibition reduced viability of $\mathrm{CD} 138^{+}$plasma cells while sparing CD138- cells from bone marrow of newly diagnosed MM patients or patients whose disease relapsed after 1 - 4 lines of treatment in both US- and EU-based cohorts. IRE1 $\alpha$ inhibition preserved survival and glucose-induced insulin secretion by pancreatic microislets. Together, these results establish a strong therapeutic rationale for targeting IRE1 $\alpha$ with kinasebased small-molecule inhibitors in MM.
\end{abstract}

\title{
Significance statement
}

Multiple myeloma (MM) is a lethal malignancy of plasma cells. MM cells have an expanded endoplasmic reticulum (ER) that is constantly under stress due to immunoglobulin hyperproduction. The ER-resident sensor IRE1 $\alpha$ mitigates ER stress by expanding the ER's protein-folding capacity while supporting proteasomal degradation of misfolded ER proteins.

IRE1 $\alpha$ elaborates these functions by deploying its cytoplasmic kinase-RNase module to activate the transcription factor XBP1s. The validity of IRE1 $\alpha$ as a potential therapeutic target in MM has been questioned. Using genetic and pharmacologic disruption in vitro and in vivo, we demonstrate that the IRE1 $\alpha$-XBP1s pathway plays a critical role in MM growth. We further show that IRE1 $\alpha$ 's kinase domain is an effective and safe potential small-molecule target for MM therapy. 


\section{Introduction}

$\mathrm{MM}$ is the second most common human hematologic cancer. It carries a lifetime risk of $0.7 \%$ and occurs mainly in older individuals. MM is caused by bone marrow infiltration of malignant, monoclonal immunoglobulin (Ig-)-secreting plasma cells (1). Despite significant therapeutic advances - including proteasome inhibitors (PIs), immunomodulatory agents (IMiDs), and antiCD38 antibodies-MM remains mainly incurable, with acquired resistance to all available agents, and 5-year survival of 49\% (2). Hence, considering the rapid growth of the aging population in many countries, there is an urgent need for development of novel MM therapies.

The endoplasmic reticulum (ER) assures the precise folding of newly synthesized transmembrane and secreted proteins. Upon elevations in cellular demand for protein secretionfor example, when mature B cells differentiate into Ig-secreting plasma cells_-insufficient ER capacity causes accumulation of unfolded proteins (UPs) in the ER lumen. This activates a rheostatic sensing-signaling network - dubbed the unfolded protein response (UPR) - to orchestrate ER adaptation and reestablish cellular homeostasis (3-6). The mammalian UPR employs three pivotal ER-resident transmembrane sensors: inositol-requiring enzyme 1 alpha $(\mathrm{IRE} 1 \alpha)$, protein kinase-like endoplasmic reticulum kinase (PERK), and activating transcription factor-6 (ATF6). Detection of excess UPs by the ER lumenal domain of each sensor engages its cytoplasmic moiety to expand the ER and its protein folding and degradative capacities, thus alleviating ER stress. If this corrective response fails and stress becomes overwhelming, the UPR can trigger apoptosis (7). Conserved from yeast to primates, IRE1 $\alpha$ harbors lumenal, transmembrane and cytosolic regions: The cytoplasmic part contains two tandem catalytic modules: A serine/threonine kinase and an endoribonuclease (RNase) $(8,9)$. IRE1 $\alpha$ activation involves homodimerization, trans-autophosphorylation of the cytoplasmic kinase domain, and RNase activation (9-12). The RNase triggers non-conventional splicing of the mRNA encoding X-box protein 1 (XBP1) by removing a 26-nucleotide intron to produce spliced XBP1 (XBP1s) (13). XBP1s encodes a potent transcription factor that activates multiple genes encoding chaperones, disulfide isomerases and lipid synthases, thereby facilitating biochemical and biophysical expansion of the ER (14-16). Additional XBP1s gene-targets encode components of the ER-associated degradation (ERAD) machinery, which promotes retro-translocation of UPs into the cytoplasm, followed by their ubiquitination and proteasomal disposal $(14,17)$. An additional activity of IRE1 $\alpha$ 's RNase — termed regulated IRE1-dependent RNA decay (RIDD)— 
cleaves ER-associated mRNAs, temporarily abating translational load $(18,19)$ and suppressing apoptosis $(20,21)$, which allows time for cellular adaptation.

Because plasma-cell differentiation requires IRE1 $\alpha$ and XBP1s (22-24), and because cancer cells often coopt normal stress-response pathways to support malignant growth in hostile microenvironments (25), it has been proposed that the IRE1 $\alpha$-XBP1s pathway may represent a therapeutically useful vulnerability in MM cells (26-28). Supporting this hypothesis, transgenic expression of XBP1s in B cells drove a MM-like disease in mice (29) and high XBP1s levels correlated with worse prognosis in MM patients (30). XBP1s depletion by shRNA attenuated growth of certain MM cell lines in vitro, and small-molecule inhibition of IRE1 $\alpha$ 's RNase activity with salicylaldehyde compounds attenuated human MM xenograft growth in mice (31, 32). Standard-of-care agents such as PIs are effective in MM therapy likely because their inhibition of the $26 \mathrm{~S}$ proteasome creates a backlog of ERAD substrates that cannot be efficiently degraded, thereby exacerbating ER stress (33). However, conflicting evidence suggests either positive $(33,34)$ or negative $(35)$ correlations between XBP1s levels and MM responsiveness to PI therapy. Moreover, although IRE1 $\alpha$ kinase inhibition blocked XBP1s production, it failed to attenuate MM cell growth in vitro (36). An additional concern is that the selectivity of the highly protein-reactive salicylaldehyde-based IRE1 $\alpha$ RNase inhibitors is difficult to ascertain: indeed, recent evidence demonstrates that one of these compounds causes oxidative stress due to offtarget activity (37). Thus, whether IRE1 $\alpha$ can be targeted effectively and safely to inhibit malignant MM growth remains controversial. In addition, because XBP1s depletion drives hyper-phosphorylation of IRE1 $\alpha(20,38)$, alternative, XBP1s-independent IRE1 $\alpha$ functionsfor example, activation of c-Jun N-terminal kinase (JNK) (39)_-also may impact MM cells. Another key question that remains unanswered in this context is whether IRE1 $\alpha$ can be targeted effectively and safely via its kinase domain to inhibit MM.

Our present results demonstrate that the IRE1 $\alpha-\mathrm{XBP} 1 \mathrm{~s}$ pathway plays a critical role in supporting MM cell growth in vitro in 3D culture, as well as in vivo in subcutaneous and orthometastatic tumor xenograft settings. Selective small-molecule IRE1 $\alpha$ kinase inhibition reduced viability of patient-derived malignant MM cells yet spared accompanying normal cells from bone marrow samples, and also preserved insulin secretion by pancreatic microislets. 
Together, these findings establish a compelling rationale for developing small-molecule inhibitors targeting IRE $1 \alpha$ kinase for MM therapy.

\section{Results}

Depletion of IRE1 $\alpha$ by shRNAs attenuates 3D growth of MM cell lines. Interrogation of the cancer cell line encyclopedia (CCLE) RNAseq dataset (Broad Institute, Cambridge, MA, USA) demonstrated that MM cell lines express higher mRNA levels of IRE1 $\alpha$ than all other cancer types (SI Appendix, Fig. S1A). Immunoblot (IB) analysis of 12 human MM cell lines revealed abundant IRE1 $\alpha$ protein, often in conjunction with detectable XBP1s protein (Fig. 1A), suggesting frequent IRE1 $\alpha-\mathrm{XBP} 1 \mathrm{~s}$ pathway activation in MM cells. To investigate the importance of IRE1 $\alpha$ for MM cell growth, we first used a doxycycline- (Dox-) inducible shRNA-based knockdown approach. As expected, Dox-driven anti-IRE1 $\alpha$ shRNA expression markedly decreased IRE1 $\alpha$ and XBP1s protein levels in KMS11, OPM2 and RPMI8226 MM cells (Fig. 1B). Importantly, Dox-induced IRE1 $\alpha$ depletion markedly inhibited 3D growth of these three cell lines in the form of single spheroids on ultra-low attachment plates, as evident by fluorescence imaging (Fig. 1C-H). IRE1 $\alpha$ knockdown also inhibited 3D growth of KMS11 cells in the form of multiple spheroids on matrigel, as determined via an Incucyte ${ }^{\mathrm{TM}}$ instrument (SI Appendix, Fig. S1B-E). Of note, similar Dox treatment did not alter growth or viability of the parental KMS11 cells (SI Appendix, Fig. S1B, D and $\boldsymbol{F}$ ), or parental OPM2 and RPMI8226 cells (data not shown). In concert with the growth inhibition, IRE1 $\alpha$ depletion in KMS11 cells cultured on matrigel led to a substantial and specific loss of viability, as measured by a CellTiterGlo $^{\circledR}$ assay (SI Appendix, Fig. S1F-H). Thus, three genetically diverse MM cell lines (40) displayed significant dependence on IRE1 $\alpha$ for 3D growth - a modality that more faithfully reflects in vivo tumor settings than the conventional 2D culture used in earlier work (36).

\section{Genetic disruption of IRE1 $\alpha$ or XBP1s attenuates growth of subcutaneous human MM} xenografts. We next disrupted the IRE1 $\alpha$ gene in KMS11 cells using CRISPR/Cas9 gene editing. In contrast to parental KMS11 cells, three independent IRE1 $\alpha$ KO clones showed a complete absence of IRE1 $\alpha$ protein and failed to upregulate XBP1s in response to the ER 
stressor thapsigargin (Tg) (SI Appendix, Fig. S2A). Upon subcutaneous injection into C.B-17 SCID mice, wildtype (WT) KMS11 cells formed readily palpable tumors that reached a mean volume of $\sim 500 \mathrm{~mm}^{3}$ by 29 days; in contrast, all three IRE1 $\alpha$ KO KMS11 clones failed to sustain appreciable tumor growth (Fig. 2A; SI Appendix, Fig. S2B). Thus, subcutaneous establishment and growth of KMS11 MM xenografts in mice requires IRE1 $\alpha$.

To examine the relative importance of XBP1s for MM tumor growth, we disrupted the XBP1 gene by CRISPR/Cas9 in KMS11 cells. Similar to the IRE1 $\alpha$ KO clones, two independent XBP1 KO clones failed to grow appreciably upon subcutaneous injection into Cb.17-SCID mice, while parental WT cells formed tumors as expected (Fig. 2B; SI Appendix, Fig. S2C). Thus, in vivo growth of KMS11 xenografts requires XBP1s. Mechanistically, IRE1 $\alpha$ KO decreased the in vitro mRNA levels of several XBP1s target genes encoding key components of the cellular ERAD machinery $(14,17)$, i.e., the E3 ubiquitin ligase SYVN1, the E2 ubiquitin-conjugating enzyme UBE2J1, and factors required for the recognition and extraction of terminally misfolded proteins from the ER, such as EDEM1, DERL2, VIMP, DNAJC10, and ERLEC1 (SI Appendix, Fig. S2D). It also attenuated secretion and increased cellular retention of IgG by cultured MM cells (SI Appendix, Fig. S2E). Furthermore, in vivo IRE1 $\alpha$ depletion in a subcutaneous RPMI8226 xenograft model inhibited secretion into the bloodstream of several cytokines, including vascular endothelial growth factor (VEGF), interleukin (IL)-6, IL-10 and IL-1 $\alpha$, as well as of certain chemokines, including IL-8 (CXCL8) and interferon-inducible protein (IP)-10 (CXCL10) (Fig. 2C). The perturbation of both ERAD and of secretory functions in MM cells lacking IRE1 $\alpha$ may compromise their in vivo growth $(23,41)$.

To ascertain whether IRE $1 \alpha$ depletion alone or in combination with standard anti-MM therapies affects growth of pre-established tumors, we allowed subcutaneously implanted KMS11 or RPMI8226 cells carrying Dox-inducible IRE1 $\alpha$ shRNAs to form palpable tumors of $\sim 200 \mathrm{~mm}^{3}$, and only then induced depletion by Dox treatment. IRE1 $\alpha$ knockdown substantially suppressed tumor progression, in conjunction with a marked decrease in XBP1s protein levels; this led to 61\% tumor-growth inhibition (TGI) in KMS11 and 70\% TGI in RPMI8226 xenografts (Fig. 2D and $\boldsymbol{E}$; SI Appendix, Fig. S2F-I). Furthermore, treatment in the KMS11 model with the maximum tolerated dose (MTD) of the PI bortezomib led to 54\% TGI, while the combination of IRE1 $\alpha$ knockdown with bortezomib afforded 91\% TGI ( $p<0.05$ compared to IRE1 $\alpha$ 
knockdown alone) (Fig. 2D; SI Appendix, Fig. S2F), indicating strong tumor attenuation. Similarly, treatment in the RPMI8226 model with the MTD of the IMiD lenalidomide led to $61 \%$ TGI, while the combination of IRE1 $\alpha$ depletion with lenalidomide achieved $110 \%$ TGI $(\mathrm{p}<0.01$ compared to IRE1 $\alpha$ knockdown alone) (Fig. 2E; SI Appendix, Fig. S2G), indicating complete tumor suppression or regression. Together, these results show that genetic disruption of IRE1 $\alpha$ markedly inhibits MM tumor initiation and progression, and increases sensitivity to established agents. Clinically, the perturbation of IRE1 $\alpha$ has the potential to cooperate significantly with existing treatment modalities to enhance the efficacy of anti-MM therapy.

\section{Small-molecule inhibition of IRE1 $\alpha$ kinase attenuates subcutaneous and orthometastatic growth of human MM xenografts. Next, we investigated whether pharmacologic inhibition of} IRE1 $\alpha$ could recapitulate the impact of genetic disruption on MM tumor growth. Because XBP1s depletion through direct IRE1 $\alpha$ RNase inhibition can lead to hyper-phosphorylation of the kinase domain $(20,42)$, we chose to block IRE1 $\alpha$ further upstream, at its kinase level. To test whether IRE1 $\alpha$ auto-phosphorylation controls RNase activation in MM cells, we transfected KMS11 IRE1 $\alpha$ KO cells with cDNA expression plasmids encoding WT or mutant variants of IRE1 $\alpha$ enzymatically deficient in kinase activity (D688N) or auto-phosphorylation on the kinaseactivation loop (S724A S726A S729A triple mutant). Upon ER stress, cells expressing WT IRE1 $\alpha$, but not the kinase-dead or auto-phosphorylation-deficient mutants, displayed elevated production of XBP1s mRNA and protein (Fig. 3A). Thus, disruption of either the kinase function or the auto-phosphorylation sites of IRE1 $\alpha$ in MM cells blocks RNase activation and XBP1s production.

Harrington et al (36) identified kinome-selective inhibitors of IRE1 $\alpha$ kinase, including compounds 16 and 18. We synthesized both molecules and confirmed their binding to a recombinant IRE $1 \alpha$ protein comprising the kinase and RNase domains, and their ability to inhibit its RNase activity toward a synthetic XBP1-based RNA substrate, as well as cellular IRE1 $\alpha$ activity measured by an XBP1s-luciferase reporter assay (SI Appendix, Fig. S3A) (11, 24). We compared the kinase selectivity of these compounds by testing 220 kinases via KinomeScan $^{\mathrm{TM}}$. Compound 18 displayed significantly better selectivity than 16, with $>70 \%$ inhibition of only one off-target kinase (JNK2), as compared to eight for 16 (SI Appendix, Fig. 
S3B). Of note, two different JNK-specific inhibitors, SP600125 and JNK-IN-8, did not impact growth of KMS11 cells at concentrations of up to $10 \mu \mathrm{M}$ (data not shown). Furthermore, mRNA expression of JNK2 in RPMI8226 and OPM2 cells was relatively low as compared to most other cell lines in the CCLE dataset (SI Appendix, Fig. S3C), suggesting that any off-target inhibition of JNK2 by 18 in these MM cell lines is unlikely to be functionally significant. Quantitative PCR analysis further demonstrated that $\mathbf{1 8}$ inhibited the constitutive IRE1 $\alpha$-mediated XBP1s production observed in RPMI8226 cells as well as ER-stress-induced XBP1s mRNA generation and RIDD activity toward DGAT2 mRNA in KMS11 cells, with half-maximal inhibitory concentrations ( $\left.\mathrm{IC}_{50}\right)$ of 30-60 nM (SI Appendix, Fig. S3D-G).

To gain structural insight into the interaction of compound 18 with its target, we cocrystallized it with the purified recombinant IRE1 $\alpha$ kinase-RNase protein and determined an Xray structure at $2.20 \AA$ resolution. Compound 18 binds in the ATP docking site (Fig. 3C; SI Appendix, Fig. S3G), consistent with its ability to act as a kinase inhibitor of IRE1 $\alpha$. The aminopyrimidine anchors at the hinge and delivers the chloro-phenyl tail moiety to the kinase back-pocket. The sulfonamide forms hydrogen bonds with the Asp, Phe, Gly (DFG) backbone in a DFG-in conformation and accepts a hydrogen bond from the catalytic Lys residue, K599. The Lys-Glu salt-bridge typically seen in the active state of kinases is absent in this structure, as K599 and E612 are separated by $5.4 \AA$. The combined effects of back-pocket binding and saltbridge disruption may induce critical structural changes throughout the cytoplasmic region that ultimately afford allosteric inhibition of the RNase. This ligand-binding mode is reminiscent of the interaction of 16 with IRE1 $\alpha$ (PDB entry 4U6R) (36). However, the 1,4 substituted naphthyl linker of 18 pulls back from the kinase N-lobe by $\sim 1.0 \AA$ as compared to the 1,5 substituted naphthyl linker of 16. Further comparison reveals that 18 displaces the $\mathrm{C}$-terminal end of the $\mathrm{C} \alpha$ helix to a greater extent than does 16 (Fig. 3D), where residue Y628 shows the most difference in sidechain conformation. Although we cannot rule out that crystal packing may influence this, structural changes in the $\mathrm{C} \alpha$-helix may contribute to the improved selectivity of $\mathbf{1 8}$ against IRE1 $\alpha$ : We therefore chose the latter molecule as a tool for further studies.

Compound 18 was not suitable for oral dosing (data not shown). However, upon intraperitoneal dosing at $30 \mathrm{mg} / \mathrm{kg}$ once or twice per day in C.B-17 SCID mice, 18 achieved initial plasma concentrations of $\sim 5 \mu \mathrm{M}$, and remained above $0.1 \mu \mathrm{M}$ for $\sim 8 \mathrm{hr}$ (SI Appendix, Fig. S4A). These data suggested potentially sufficient exposure to this compound to attain 
significant, though perhaps incomplete, IRE1 $\alpha$ inhibition in vivo. Comparable to the effect of IRE $1 \alpha$ shRNA depletion, treatment of mice bearing pre-established KMS11 or OPM2 tumors with 18 over 23 or 11 days, respectively, led to a substantial reduction in XBP1s protein, in conjunction with $51 \%$ or $70 \%$ TGI, respectively (Fig. $4 \boldsymbol{A}$ and $\boldsymbol{B}$; SI Appendix, Fig. S4B-E). Thus, pharmacologic IRE1 $\alpha$ kinase inhibition recapitulated the impact of shRNA-based IRE1 $\alpha$ disruption on growth of MM xenografts.

We then turned to a more stringent orthometastatic model of MM, in which luciferase and mCherry double-labeled RPMI8226 cells, injected into the tail vein of NSG mice, develop widespread malignant disease with bone marrow involvement over a period of 6 weeks (SI Appendix, Fig. S4F) (43). Daily treatment of mice bearing established malignant disease with compound 18 over two subsequent weeks led to a substantial reduction in tumor burden, as evident by diminished luminescence (Fig. 4C): Whereas 3/3 control mice displayed tumor progression over baseline, only 1/5 18-treated mice showed tumor progression, while another $1 / 5$ exhibited tumor stasis, and 3/5 showed substantial tumor regression. Thus, pharmacologic inhibition of IRE1 $\alpha$ kinase in vivo can disrupt growth of MM xenografts not only in the subcutaneous setting but also in the more clinically relevant orthometastatic bone marrow microenvironment.

\section{IRE1 $\alpha$ kinase inhibition reduces viability of patient-derived MM cells while sparing}

normal cells. MM cell lines may acquire further genetic or epigenetic alterations upon prolonged passage that could diverge from primary MM cells. Therefore, to gain a more direct appraisal of the importance of IRE1 $\alpha$ for primary MM cell survival, we tested the effect of compound $\mathbf{1 8}$ on viability of primary CD $138^{+} \mathrm{MM}$ cells, from bone marrow or peripheral blood samples donated by MM patients treated in the USA and EU (SI Appendix, Fig. S5 $\boldsymbol{A}$ ). Incubation over two days with 18 led to marked reductions in viability of the malignant CD138 ${ }^{+} \mathrm{MM}$ cells, but not the associated non-malignant CD138- cells, in the majority of MM samples (Fig. $5 \boldsymbol{A}$ and $\boldsymbol{B}$ ). Samples in both cohorts from newly diagnosed patients as well as subjects whose MM relapsed after 1-4 prior lines of therapy showed dose-dependent sensitivity to $\mathbf{1 8}$ (Fig. $\mathbf{5 C}$ and $\boldsymbol{D}$ ). Four additional relapsed MM samples did not show significant loss of viability (data not shown). Importantly, exposure to $\mathbf{1 8}$ did not reduce the viability of $\mathrm{CD} 138^{+}$cells from three nonmalignant bone marrow aspirates (Fig. 5E). Thus, IRE1 $\alpha$ kinase inhibition can selectively 
disrupt survival of primary malignant MM cells while sparing nonmalignant marrow cells, including plasma cells. The impact on both naiive and post-treatment relapsed MM samples suggests that IRE1 $\alpha$ inhibition has the potential to provide clinical benefit across multiple lines of therapy.

Inducible gene-knockout studies in mice have suggested that the IRE1 $\alpha$-XBP1s pathway may support insulin secretion by pancreatic cells $(44,45)$. To examine whether pharmacologic IRE1 $\alpha$ kinase inhibition would affect these cell types, we first verified the ability of compound 18 to inhibit XBP1s induction in human pancreatic islet 3D microtissues, which contain all the endocrine cell types and can retain viability and function in culture for up to 4 weeks (46). At 2.4 $\mu \mathrm{M}, 18$ suppressed Tg-induced XBP1s production to baseline levels (Fig. $6 \boldsymbol{A}$ ), confirming effective IRE1 $\alpha$ pathway inhibition. Importantly, 18 did not decrease viability, nor did it perturb glucose-stimulated insulin secretion even at higher concentrations up to $7.5 \mu \mathrm{M}$ (Fig. $\mathbf{6 B}$ and $\boldsymbol{C}$ ). We obtained similar results with rat pancreatic microislets (SI Appendix, Fig. S6 A and B). Together, these results suggest that IRE1 $\alpha$ kinase inhibition may achieve significant MM tumor disruption without overt negative effects on pancreatic endocrine homeostasis.

\section{Discussion}

It has been proposed that MM cells may coopt the IRE1 $\alpha$-XBP1s pathway to mitigate persistent ER stress, caused by excessive Ig production and a nutrient/oxygen-poor bone marrow microenvironment (27). However, recent studies have raised significant doubt concerning the validity of IRE $1 \alpha$ as a potential therapeutic target: Lowered levels of XBP1s correlated with PI resistance in MM cells (35), and IRE1 $\alpha$ kinase inhibition blocked XBP1s yet did not affect MM cell viability in 2D culture $(35,36)$. Moreover, loss-of-function studies directly and specifically addressing the importance of IRE1 $\alpha$ 's kinase module for MM growth have been lacking. Although work based on salicylaldehyde small-molecule RNase inhibitors supported a protumorigenic role of IRE1 $\alpha$ in $\operatorname{MM}(31,32)$, a key caveat is that such compounds are highly protein-reactive, and their selectivity versus other RNases and other targets is likely to be poor (37). 
To interrogate the requirement of IRE1 $\alpha$ for MM growth, we employed a series of strategies to disrupt it at the gene, transcript, or kinase level, in diverse model systems. Our in vitro studies showed that IRE1 $\alpha$ depletion by shRNA markedly attenuates growth of several MM cell lines in 3D spheroid settings - a scenario that was not previously investigated. Both IRE1 $\alpha$ $\mathrm{KO}$ and XBP1s KO by CRISPR/Cas9 in KMS11 MM cells profoundly disrupted their ability to form subcutaneous tumor xenografts in mice. These findings demonstrate a critical requirement for the IRE1 $\alpha$ pathway for in vivo MM growth, while other XBP1s-independent functions of IRE1 $\alpha$ such as RIDD and JNK activation may be less crucial in this context. IRE1 $\alpha$ depletion by shRNA also inhibited growth of pre-formed subcutaneous KMS11 and RPMI8226 tumor xenografts, implicating IRE1 $\alpha$ in promoting not only tumor initiation but also tumor progression. Mechanistically, IRE1 $\alpha$ knockdown decreased mRNA expression of specific ERAD components known to be induced by XBP1s, and it compromised the ability of MM cells to secrete Ig as well as several important cytokines and chemokines, some of which have previously been shown to support malignant plasma cell growth in vitro and in vivo $(1,23,33,41)$. Remarkably, the extent of TGI was comparable between IRE1 $\alpha$ knockdown and the well-established frontline MM therapy agents bortezomib or lenalidomide. Furthermore, combination of IRE1 $\alpha$ depletion with bortezomib or lenalidomide significantly increased the extent of TGI as compared to respective monotherapies. Together, these results suggest that IRE1 $\alpha$ inhibition may provide clinical benefit, either alone or in combination with other MM therapies known to disrupt protein homeostasis $(33,47)$.

To examine more directly the requirement for IRE1 $\alpha$ 's kinase moiety, we first confirmed its importance for RNase activation by mutational perturbation of the kinase catalytic core or its target autophosphorylation sites. We then evaluated two compounds that bind to IRE1 $\alpha$ 's ATP docking site and exert allosteric inhibition of RNase activation (36). One of these showed an improved ability to displace the $\mathrm{C} \alpha$ helix in the kinase domain, with excellent selectivity toward IRE1 $\alpha$ versus 220 other kinases. This compound displayed sufficient tolerability and plasma exposure upon intraperitoneal administration in vivo to enable substantial inhibition of XBP1s production in tumors. Moreover, it significantly attenuated subcutaneous growth of KMS11 and OPM2 xenografts. Thus, pharmacologic inhibition of IRE1 $\alpha$ via its kinase moiety recapitulated the impact of genetic IRE1 $\alpha$ disruption on MM tumor growth. 
To address the importance of IRE1 $\alpha$ for MM growth in a more clinically relevant microenvironment, we used an orthometastatic model, in which malignant MM cells injected intravenously home to the bone marrow to disseminate malignant disease. Treatment with the IRE1 $\alpha$ kinase inhibitor in this setting led to tumor stasis or regression in most of the compoundtreated animals, as compared to aggressive tumor progression in vehicle-treated controls. Thus, MM cells require IRE1 $\alpha$ activity to sustain advanced malignant growth based in the bone marrow microenvironment.

Establishing the excellent kinase selectivity of compound $\mathbf{1 8}$ afforded us a unique opportunity to examine more reliably the impact of specific IRE1 $\alpha$ inhibition on patient-derived MM cells. Remarkably, the compound caused a substantial reduction in viability of malignant $\mathrm{CD} 138^{+}$cells in most of the MM patient samples. Importantly, these included newly diagnosed tumors as well as some tumors that relapsed after up to four lines of prior therapy with PI and/or IMiD and/or other agents. In contrast, 18 did not significantly reduce viability of accompanying nonmalignant CD138 - cells in the same MM aspirates; it also spared both $\mathrm{CD} 138^{+}$plasma cells and CD138 - cells in nonmalignant bone marrow samples. Furthermore, while achieving complete XBP1s suppression, 18 disrupted neither the overall viability of human and rat pancreatic microislets, nor their capacity to secrete insulin in response to glucose challenge. Taken together, these results suggest that malignant MM cells may harbor a greater dependency on the IRE1 $\alpha$-XBP1s pathway than do nonmalignant secretory cell types including normal bone marrow plasma cells, highlighting the importance of this pathway as a unique vulnerability that could be clinically exploited to treat MM across multiple stages. An effort to develop orally available compounds to target IRE $1 \alpha$ kinase and a more comprehensive safety analysis in suitable model organisms would be needed in order to enable future human testing of IRE1 $\alpha$ inhibitors in clinical trials.

In conclusion, our studies provide definitive preclinical evidence validating IRE1 $\alpha$ as a potential therapeutic target for MM. IRE1 $\alpha$ may play an important role in augmenting malignant growth of MM cells by enabling their adaptation to chronic ER stress through elevated ERAD capacity. IRE1 $\alpha$ may also support the secretion of cytokines and chemokines that enable survival and growth of malignant MM cells in their metabolically restrictive bone marrow microenvironment. Finally, our findings provide proof of concept that the kinase domain of 
IRE $1 \alpha$ is an effective and potentially safe lever for small-molecule inhibition of this dualfunction enzyme both in vitro and in vivo. This work therefore presents a compelling rationale to develop clinical-grade IRE1 $\alpha$ kinase-disrupting agents for MM therapy.

\section{Material and Methods}

Detailed methods are provided in SI Appendix.

Cell culture and experimental reagents. KMS11, RPMI8226, OPM2, H929, KMS27, MOLP8, LP1, U266.B1, UTMC2, KMM1, KMS28PE and MOLP2 cells were obtained from ATCC, JCRB, or DSMZ, authenticated by short tandem repeat (STR) profiles, and tested to ensure mycoplasma free within 3 months of use. All cell lines were cultured in RPMI1640 media supplemented with 10\% (v/v) fetal bovine serum (FBS, Sigma), 2 mM glutaMAX (Gibco) and $100 \mathrm{U} / \mathrm{ml}$ penicillin plus $100 \mu \mathrm{g} / \mathrm{ml}$ streptomycin (Gibco).

Thapsigargin (Sigma) was used at a concentration of $100 \mathrm{nM}$, tunicamycin (Sigma) at 5 $\mu \mathrm{g} / \mathrm{ml}$. Compound 16/ 16 and compound 18/18 (36) were dissolved in DMSO for cellular experiments, and used at the indicated concentrations. Antibodies (Abs) for IRE1 $\alpha$ (\#3294), $\beta$ actin (\#3700) and GAPDH (\#5174) were from Cell Signaling Technology. Ab for human IgG (\#109489) was from Abcam. Abs for XBP1s and pIRE1 (21) were generated at Genentech. Secondary antibody (\#711-035-152) was from Jackson Laboratories.

3D spheroid proliferation assays. RPMI8226 IRE1 $\alpha$ sh7-5-mCherry, OPM2 IRE1 $\alpha$ sh9mCherry and KMS11 $\alpha$ IRE1 sh8-9-mCherry cells were pre-treated with $0.5 \mu \mathrm{g} / \mathrm{ml}$ doxycycline for 3 days before plating 1000 cells/ well in ultra-low attachment (ULA) 96-well plates (Corning). Single tumor spheroids were formed by centrifugation (1,000 rpm) for $10 \mathrm{~min}$ according to manufacturer's protocol. Spheroids were imaged using a real-time imaging system (IncuCyte ${ }^{\mathrm{TM}}$, Essen Bioscience, Ann Arbor, Michigan). Frames were captured at 4-hr intervals using a $4 \mathrm{x}$ or 10x objective and red fluorescence was detected.

For Matrigel assays, KMS11 IRE1 $\alpha$ sh8-9 cells were pre-treated with $0.5 \mu \mathrm{g} / \mathrm{ml}$ doxycycline for 3 days before plating 1000-5000 cells/well on $50 \mu \mathrm{l} /$ well of Matrigel (Corning) into 96 well plates according to manufacturer's protocol. Spheroids images were captured at 4-hr 
intervals using a 10x objective. Cell viability was assessed using an ATP-consumption assay (CellTiter-Glo® 3D, Promega) and measured in a luminescence reader (Envision, Perkin Elmer). Cultures were maintained at $37^{\circ} \mathrm{C}$ throughout and run at least in triplicates. Values well were pooled and averaged across all replicates.

Pancreatic islet 3D microtissue assays. Human and rodent 3D InSight ${ }^{\mathrm{TM}}$ pancreatic islet microtissues (InSphero AG) were produced from reconstituted dispersed human or rat pancreatic islet cells in a modified manner as described previously (46) retaining the composition of $\alpha, \beta$ and $\delta$ cells representative of normal endocrine pancreatic islets. Cells were plated in microtiter wells (1000 cells/drop), and allowed to form 3D microtissues of $\sim 120 \mu \mathrm{M}$ in diameter over 7 days ( $\mathrm{n}=5$ per treatment). Microtissues were incubated for 7 days with serial dilutions of compound 18 or vehicle control, and then viability analyzed by CellTiter-Glo® (Promega), or insulin secretion analyzed after glucose challenge for 2 hours $(16.7 \mu \mathrm{M})$ by ELISA.

Human MM samples. The effect of compound 18 on viability of MM or normal cells was measured after a $48 \mathrm{hr}$ treatment in ex vivo culture of bone marrow aspirates or blood samples from MM patients or from normal bone marrow donors. For cell death assays, mononuclear cells (MNC) obtained after separation on Ficoll density gradient where cultured in RPMI1640 media supplemented with 5\% FCS and $3 \mathrm{ng} / \mathrm{ml} \mathrm{IL-6,} \mathrm{with} \mathrm{the} \mathrm{indicated} \mathrm{concentrations} \mathrm{of} \mathrm{compound} 18$ for $48 \mathrm{hr}$. MM cells were then identified using CD138-PE staining and cell death was assessed by the loss of CD138 staining as previously described (48). MM or normal plasma cells were identified as $\mathrm{CD}^{-} 9^{-}, \mathrm{CD} 45^{-} / \mathrm{dim}, \mathrm{CD} 38^{+}, \mathrm{CD} 138^{+}$, and $\mathrm{CD} 46^{+}$.

Subcutaneous xenograft growth and efficacy studies. All procedures were approved by and conformed to the guidelines and principles set by the Institutional Animal Care and Use Committee (IACUC) of Genentech and were carried out in an Association for the Assessment and Accreditation of Laboratory Animal Care (AAALAC)-accredited facility.

For tumor growth studies, 10x10 $10^{6} \mathrm{KMS} 11 \mathrm{WT}$, IRE1 $\alpha$ KO or XBP1 KO clones, respectively, were suspended in HBSS, admixed with 50\% Matrigel (Corning) to a final volume of $100 \mu \mathrm{l}$, and injected subcutaneously in the right flank of 6 to 8-week old female CB-17 SCID mice. 
For efficacy studies, $10 \times 10^{6}$ KMS11 IRE1 $\alpha$ sh8-9, RPMI8226 IRE1 $\alpha$ sh5-7 or OPM2 IRE1 $\alpha$ sh9 cells were prepared and subcutaneously inoculated as outlined above. Tumors were monitored until they reached a mean tumor volume of approximately 150 to $300 \mathrm{~mm}^{3}$. For efficacy studies of IRE1 shRNA knockdown in combination with standard of care agents, bortezomib (Velcade $\AA$, Millennium Pharmaceuticals) or lenalidomide (Revlimid $\AA$, Celgene Corp.), animals were randomized into the following treatment groups: (i) 5\% sucrose water (provided in drinking water, changed weekly); (ii) doxycycline $(0.5 \mathrm{mg} / \mathrm{ml}$, dissolved in $5 \%$ sucrose water, changed $3 \mathrm{x} /$ week); (iii) bortezomib $(0.75 \mathrm{mg} / \mathrm{kg}, 100 \mu \mathrm{L}$ total, intravenously, twice per week) or lenalidomide $(50 \mathrm{mg} / \mathrm{kg}, 100 \mu \mathrm{L}$ total, intraperitoneally, once daily for 5 consecutive days), respectively; and (iv) combination of doxycycline plus bortezomib, or doxycycline plus lenalidomide, respectively.

For the compound 18 efficacy studies, animals were randomized into one of three following treatment groups: (i) vehicle controls (35\% PEG400 and 10\% EtOH in water, $100 \mu \mathrm{L}$ total, intraperitoneally, dosed once daily) and 5\% sucrose water (provided as drinking water, changed weekly); (ii) doxycycline $(0.5 \mathrm{mg} / \mathrm{ml}$, dissolved in $5 \%$ sucrose water, changed $3 \mathrm{x} /$ week); (iii) compound $18(30 \mathrm{mg} / \mathrm{kg}, 100 \mu \mathrm{L}$ total, intraperitoneally, dosed QD or BID as indicated in Figure legends).

Orthometastatic xenograft efficacy studies. For the orthometastatic xenograft model, $1 \times 10^{6}$ RPMI8226-mCherry-Luc cells were injected intravenously via the tail vein of non-irradiated 8week old female NOD/SCID/IL2ry-/- mice (NSG, Jackson Laboratories). The animals were imaged weekly under isoflurane anesthesia 5 min after intraperitoneal luciferin injection with $200 \mu \mathrm{l}$ of $25 \mathrm{mg} \mathrm{ml}^{-1}$ D-luciferin (Invitrogen), and imaged on a Photon Imager (BioSpace Laboratory). During image acquisition, animals continued to receive anesthesia from a nosecone delivery system, while their body temperatures were maintained on a thermostatically controlled platform. Photon counts per min per $\mathrm{cm}^{2}$ of observational area were calculated and compared using M3 Vision software (BioSpace Laboratory). After 6 weeks mice were grouped out into the following treatment groups: (i) vehicle control (35\% PEG400 and 10\% EtOH in water, $100 \mu \mathrm{L}$ total, intraperitoneally, QD); or (ii) compound 18 (30 mg/kg, $100 \mu \mathrm{L}$ total, intraperitoneally, QD). After 14 days, mice were euthanized by cervical dislocation and bones harvested for fluorescence imaging using a Kodak In-Vivo FX system (Carestream 
Health Molecular Imaging, New Haven, Connecticut) and Carestream Molecular Imaging (MI) Software. Excitation and emission wavelengths were fixed at $550 \mathrm{~nm}$ and $600 \mathrm{~nm}$, respectively. Fluorescence images were co-registered with X-ray images using the opensource software Image J (http://rsbweb.nih.gov/ij/).

Statistics. Statistical analysis of the results was performed by unpaired, two-tailed t-test. Comparison of three or more columns was performed using a one-way ANOVA followed by Turkey's procedure. A P value $<0.05$ was considered significant. All statistical analyses were performed using GraphPad Prism 6 (GraphPad Software, Inc.). For further information regarding statistical analysis, please see section regarding xenograft studies above.

\section{Acknowledgments}

This work was supported in part by an Irvington Postdoctoral Fellowship of the Cancer Research Institute to DAA and by a Howard Hughes Collaborative Innovation Award to PW. PW is an Investigator of the Howard Hughes Medical Institute.

We thank Rena Wang and Xiangnan Du for help with cell line generation, Brian Rabinovich for mCherry lentiviral construct design, members of the Ashkenazi and Walter labs, Marc Shuman, Stephen Gould, Matthew Wright, Shiva Malek, Daniel Sutherlin, Jessica Sims, Wendy Lee, and Ira Mellman for helpful discussions.

\section{Conflict of interest}

J.M.H., A.L.T., S.A.M., D.A.L., M.L., Y.-C.A.C., J.Q., K.T., D.K., E.S., H.A.W., W.W., K. C., S.K., M.B., W.S., M.L., J.W., J.L., T.D.B., A.H., B.H., A.G., R.W., D.L., M.-G.B., J.R. and A.A. were employees of Genentech, Inc. during performance of this work. P.W (UCSF employee) has a patent. Rights to the invention have been licensed by UCSF to Genentech.

\section{Author contributions}

J.M.H., A.L.T., S.A.M., D.A.L., M.L. and Y.-C.A.C. designed, performed and analyzed the experiments. J.Q. generated KMS11, OPM2 and RPMI IRE1 $\alpha$ shRNA cell lines. K.T., D.K. 
and E.S. helped perform in vivo studies. H.A.W. and W.W. designed, performed and analyzed crystallographic studies. K.C., S.K. and M.B. developed assays and characterized Compound 16 and 18 in vitro. W.S., M.L. and J.W. helped generate, purify and biochemically characterize recombinant IRE $1 \alpha$ proteins. J.L. and T.D.B. performed pharmacokinetic studies. S.A.M., A.H. and B.H. designed and generated key shRNA, gRNA and DNA constructs and corresponding genetically-engineered cell lines. A.G. and R.W. helped design, conduct and analyze in vivo bioimaging studies. D.L. helped design, perform and interpret safety studies. M.-G.B. and J.R. helped coordinate chemical synthesis and contributed to experimental design and data interpretation. M.J.V., D.W.S., P.G.-B. and M.A. designed, performed and interpreted primary MM patient sample analysis. D.A.-A. and P.W. contributed to experimental design, model development and data interpretation. J.M.H. and A.A. designed the experiments, interpreted the data and co-wrote the manuscript with input from all authors. 


\section{References}

1. Kuehl WM \& Bergsagel PL (2002) Multiple myeloma: evolving genetic events and host interactions. Nat Rev Cancer 2(3):175-187.

2. Siegel RL, Miller KD, \& Jemal A (2015) Cancer statistics, 2015. CA Cancer J Clin 65(1):5-29.

3. Walter P \& Ron D (2011) The unfolded protein response: from stress pathway to homeostatic regulation. Science 334(6059):1081-1086.

4. Hetz C (2012) The unfolded protein response: controlling cell fate decisions under ER stress and beyond. Nat Rev Mol Cell Biol 13(2):89-102.

5. Wang M \& Kaufman RJ (2016) Protein misfolding in the endoplasmic reticulum as a conduit to human disease. Nature 529(7586):326-335.

6. Cubillos-Ruiz JR, Bettigole SE, \& Glimcher LH (2017) Tumorigenic and Immunosuppressive Effects of Endoplasmic Reticulum Stress in Cancer. Cell 168(4):692-706.

7. Tabas I \& Ron D (2011) Integrating the mechanisms of apoptosis induced by endoplasmic reticulum stress. Nat Cell Biol 13(3):184-190.

8. Cox JS, Shamu CE, \& Walter P (1993) Transcriptional induction of genes encoding endoplasmic reticulum resident proteins requires a transmembrane protein kinase. Cell 73(6):1197-1206.

9. Lee KP, et al. (2008) Structure of the dual enzyme Irel reveals the basis for catalysis and regulation in nonconventional RNA splicing. Cell 132(1):89-100.

10. Tirasophon W, Welihinda AA, \& Kaufman RJ (1998) A stress response pathway from the endoplasmic reticulum to the nucleus requires a novel bifunctional protein kinase/endoribonuclease (Ire1p) in mammalian cells. Genes Dev 12(12):1812-1824.

11. Korennykh AV, et al. (2009) The unfolded protein response signals through high-order assembly of Ire1. Nature 457(7230):687-693.

12. Han D, et al. (2009) IRE1alpha kinase activation modes control alternate endoribonuclease outputs to determine divergent cell fates. Cell 138(3):562-575.

13. Lu Y, Liang FX, \& Wang X (2014) A synthetic biology approach identifies the mammalian UPR RNA ligase RtcB. Mol Cell 55(5):758-770.

14. Travers KJ, et al. (2000) Functional and genomic analyses reveal an essential coordination between the unfolded protein response and ER-associated degradation. Cell 101(3):249-258.

15. Shaffer AL, et al. (2004) XBP1, downstream of Blimp-1, expands the secretory apparatus and other organelles, and increases protein synthesis in plasma cell differentiation. Immunity 21(1):81-93.

16. Acosta-Alvear D, et al. (2007) XBP1 controls diverse cell type- and condition-specific transcriptional regulatory networks. Mol Cell 27(1):53-66.

17. Brodsky JL (2012) Cleaning up: ER-associated degradation to the rescue. Cell 151(6):1163-1167.

18. Hollien J \& Weissman JS (2006) Decay of endoplasmic reticulum-localized mRNAs during the unfolded protein response. Science 313(5783):104-107.

19. Hollien J, et al. (2009) Regulated Ire1-dependent decay of messenger RNAs in mammalian cells. J Cell Biol 186(3):323-331. 
20. Lu M, et al. (2014) Opposing unfolded-protein-response signals converge on death receptor 5 to control apoptosis. Science 345(6192):98-101.

21. Chang TK, et al. (2018) Coordination between Two Branches of the Unfolded Protein Response Determines Apoptotic Cell Fate. Mol Cell 71(4):629-636 e625.

22. Reimold AM, et al. (2001) Plasma cell differentiation requires the transcription factor XBP-1. Nature 412(6844):300-307.

23. Iwakoshi NN, et al. (2003) Plasma cell differentiation and the unfolded protein response intersect at the transcription factor XBP-1. Nat Immunol 4(4):321-329.

24. Zhang K, et al. (2005) The unfolded protein response sensor IRE1alpha is required at 2 distinct steps in B cell lymphopoiesis. J Clin Invest 115(2):268-281.

25. Hanahan D \& Weinberg RA (2011) Hallmarks of cancer: the next generation. Cell 144(5):646-674.

26. Vincenz L, Jager R, O'Dwyer M, \& Samali A (2013) Endoplasmic reticulum stress and the unfolded protein response: targeting the Achilles heel of multiple myeloma. Mol Cancer Ther 12(6):831-843.

27. Wang M \& Kaufman RJ (2014) The impact of the endoplasmic reticulum protein-folding environment on cancer development. Nat Rev Cancer 14(9):581-597.

28. Jiang D, Niwa M, \& Koong AC (2015) Targeting the IRE1alpha-XBP1 branch of the unfolded protein response in human diseases. Semin Cancer Biol 33:48-56.

29. Carrasco DR, et al. (2007) The differentiation and stress response factor XBP-1 drives multiple myeloma pathogenesis. Cancer Cell 11(4):349-360.

30. Bagratuni T, et al. (2010) XBP1s levels are implicated in the biology and outcome of myeloma mediating different clinical outcomes to thalidomide-based treatments. Blood 116(2):250-253.

31. Papandreou I, et al. (2011) Identification of an Irelalpha endonuclease specific inhibitor with cytotoxic activity against human multiple myeloma. Blood 117(4):1311-1314.

32. Mimura N, et al. (2012) Blockade of XBP1 splicing by inhibition of IRE1alpha is a promising therapeutic option in multiple myeloma. Blood 119(24):5772-5781.

33. Kumar SK, et al. (2017) Multiple myeloma. Nat Rev Dis Primers 3:17046.

34. Ling SC, et al. (2012) Response of myeloma to the proteasome inhibitor bortezomib is correlated with the unfolded protein response regulator XBP-1. Haematologica 97(1):6472.

35. Leung-Hagesteijn C, et al. (2013) Xbp1s-negative tumor B cells and pre-plasmablasts mediate therapeutic proteasome inhibitor resistance in multiple myeloma. Cancer Cell 24(3):289-304.

36. Harrington PE, et al. (2015) Unfolded Protein Response in Cancer: IRE1alpha Inhibition by Selective Kinase Ligands Does Not Impair Tumor Cell Viability. ACS Med Chem Lett 6(1):68-72.

37. Chan SMH, Lowe MP, Bernard A, Miller AA, \& Herbert TP (2018) The inositolrequiring enzyme 1 (IRE1alpha) RNAse inhibitor, 4micro8C, is also a potent cellular antioxidant. Biochem J 475(5):923-929.

38. Niederreiter L, et al. (2013) ER stress transcription factor Xbp1 suppresses intestinal tumorigenesis and directs intestinal stem cells. J Exp Med 210(10):2041-2056.

39. Urano F, et al. (2000) Coupling of stress in the ER to activation of JNK protein kinases by transmembrane protein kinase IRE1. Science 287(5453):664-666. 
40. Lombardi L, et al. (2007) Molecular characterization of human multiple myeloma cell lines by integrative genomics: insights into the biology of the disease. Genes Chromosomes Cancer 46(3):226-238.

41. Ria R, et al. (2004) A VEGF-dependent autocrine loop mediates proliferation and capillarogenesis in bone marrow endothelial cells of patients with multiple myeloma. Thromb Haemost 92(6):1438-1445.

42. Chen X, et al. (2014) XBP1 promotes triple-negative breast cancer by controlling the HIF1alpha pathway. Nature 508(7494):103-107.

43. Rozemuller $\mathrm{H}$, et al. (2008) A bioluminescence imaging based in vivo model for preclinical testing of novel cellular immunotherapy strategies to improve the graft-versusmyeloma effect. Haematologica 93(7):1049-1057.

44. Iwawaki T, Akai R, Yamanaka S, \& Kohno K (2009) Function of IRE1 alpha in the placenta is essential for placental development and embryonic viability. Proc Natl Acad Sci U S A 106(39):16657-16662.

45. Iwawaki T, Akai R, \& Kohno K (2010) IRE1alpha disruption causes histological abnormality of exocrine tissues, increase of blood glucose level, and decrease of serum immunoglobulin level. PLoS One 5(9):e13052.

46. Zuellig RA, et al. (2017) Improved physiological properties of gravity-enforced reassembled rat and human pancreatic pseudo-islets. J Tissue Eng Regen Med 11(1):109120.

47. Lu G, et al. (2014) The myeloma drug lenalidomide promotes the cereblon-dependent destruction of Ikaros proteins. Science 343(6168):305-309.

48. Surget S, et al. (2012) Cell death via DR5, but not DR4, is regulated by p53 in myeloma cells. Cancer Res 72(17):4562-4573. 


\section{Figure legends}

Fig. 1. Expression of IRE1 $\alpha$ in MM cell lines and effect of its depletion on spheroid 3D growth. (A) Twelve human MM cell lines were analyzed by immunoblot (IB) for protein levels of IRE1 $\alpha$ and XBP1s. (B) KMS11, OPM2, and RPMI8226 MM cells were stably transfected with a plasmid encoding Dox-inducible shRNA against IRE1 $\alpha$ together with a plasmid encoding mCherry. Cells were incubated in the absence or presence of Dox $(0.5 \mu \mathrm{g} / \mathrm{ml})$ for 3 days, seeded on ultra-low adhesion plates, centrifuged to form single spheroids, and analyzed by IB for indicated proteins $(\boldsymbol{B})$, or for growth based on mCherry fluorescence $(\boldsymbol{C}-\boldsymbol{E})$, or imaged by fluorescence microscopy $(\boldsymbol{F}-\boldsymbol{H})$.

\section{Fig. 2. Genetic disruption of IRE1 $\alpha$ or XBP1 attenuates growth of subcutaneous human} MM xenografts in mice. $(\boldsymbol{A}$ and $\boldsymbol{B})$ The IRE1 $\alpha(\boldsymbol{A})$ or XBP1 $(\boldsymbol{B})$ genes were disrupted by CRISPR/Cas9 technology in KMS11 cells. Parental or corresponding knockout (KO) clones were injected subcutaneously into CB.17-SCID mice and monitored for tumor growth over 29 or 30 days, respectively. ( $\boldsymbol{C}$ ) Mice bearing subcutaneous RPMI8226 tumor xenografts were treated with Dox $(0.5 \mathrm{mg} / \mathrm{kg})$ for 21 days in drinking water and analyzed for concentrations of indicated cytokines and chemokines by ELISA. (D and $\boldsymbol{E})$ KMS11 (D) or RPMI8226 (E) cells stably transfected with Dox-inducible shRNAs against IRE1 $\alpha$ were inoculated subcutaneously into C.B17-SCID mice and allowed to establish tumors of $\sim 200 \mathrm{~mm}^{3}$ in volume. Mice were then treated with sucrose or Dox in drinking water and tumors were monitored for 21 days. Alternatively, mice with established tumors were treated with the proteasome inhibitor bortezomib $(0.75 \mathrm{mg} / \mathrm{kg} \mathrm{IV})$, alone or in combination with Dox $(\boldsymbol{D})$; or the IMiD lenalidomide $(50 \mathrm{mg} / \mathrm{kg} \mathrm{IP})$, alone or in combination with Dox $(\boldsymbol{E})$. Individual tumor data are shown in SI Appendix, Fig. S2F and $G$.

Fig. 3. Importance of IRE1 $\alpha$ kinase in RNase activation and co-crystal structure of IRE1 $\alpha$ with compound 18 as compared to 16. $(\boldsymbol{A}) \mathrm{KMS} 11 \mathrm{IRE} 1 \alpha \mathrm{KO}$ cells were stably transfected with expression plasmids encoding: Wildtype (WT) IRE1 $\alpha$, or a "kinase-dead" D688N mutant of IRE1 $\alpha$, or an "auto-phosphorylation-deficient" S724A, S726A, S729A triple mutant of IRE1 $\alpha$. 
Cells were then incubated in the absence or presence of $\mathrm{Tg}(100 \mathrm{nM})$ for 3 hours, and analyzed either by IB for levels of the indicated proteins, or by RT-QPCR for mRNA levels of XBP1s. (B) Chemical structure of 18 and $\mathbf{1 6}(36)$. (C) A close-up view of the crystal structure of compound 18 in complex with the kinase-RNase portion of IRE1 $\alpha$. The protein is rendered in ribbons, with key residues in the ligand-binding pocket shown as sticks. Water molecules near the ligand are shown in red spheres. Black dash lines indicate hydrogen bonding interactions. (D) Comparison between the co-crystal structures of compound 18 (colored in wheat and orange versus 16 (PDB entry: 4U6R, colored cyan and blue) bound to IRE1 $\alpha$. The C-terminal end of the $\alpha \mathrm{C}$-helix displays significant conformational changes between the two structures.

Fig. 4. Small-molecule inhibition of IRE1 $\alpha$ kinase attenuates subcutaneous and orthometastatic growth of human MM xenografts in mice. (A) KMS11 cells stably transfected with plasmids encoding Dox-inducible shRNAs against IRE1 $\alpha$ were inoculated subcutaneously into C.B17-SCID mice and allowed to establish tumors of $\sim 200 \mathrm{~mm}^{3}$. Mice were then treated with either vehicle, Dox in the drinking water $(0.5 \mathrm{mg} / \mathrm{kg})$, or compound 18 (30 $\mathrm{mg} / \mathrm{kg}$ ) intraperitoneally twice per day and monitored for tumor growth over 24 days. Individual tumor data are shown in SI Appendix, Fig. S4C. (B) OPM2 cells stably transfected with plasmids encoding Dox-inducible shRNAs against IRE1 $\alpha$ were inoculated subcutaneously into C.B17-SCID mice and allowed to establish tumors of $\sim 160 \mathrm{~mm}^{3}$. Mice were then treated as in $\boldsymbol{A}$ with either vehicle, Dox in the drinking water, or compound 18 intraperitoneally once per day and monitored for tumor growth over 11 days. Individual tumor data are shown in SI Appendix, Fig. S4E. (C) RPMI8226 cells expressing plasmids encoding mCherry and luciferase were injected intravenously via the tail vein of NSG mice and tumors were allowed to establish in the bone marrow over a period of 6 weeks. Tumor burden was monitored by in-life imaging of luminescence. After 6 weeks, mice were grouped out based on similar tumor burden, treated with vehicle $(\mathrm{n}=3)$ or compound $18(30 \mathrm{mg} / \mathrm{kg}$, intraperitoneally, twice per day, $\mathrm{n}=5)$ for 2 weeks, and analyzed again for tumor burden. One control mouse died during anesthesia and one treated mouse was euthanized due to weight loss. Luminescence images of representative mice are depicted on the left. The tumor burden of each mouse is depicted as \% tumor growth on day 14 (at the end of 8 weeks) as compared to day 0 of treatment (at the end of 6 weeks). 
Fig. 5. Small-molecule inhibition of IRE1 $\alpha$ kinase reduces viability of $\mathrm{CD} 138^{+} \mathrm{MM}$ cells in patient-derived samples without disrupting CD138- cells. Bone marrow aspirates or peripheral blood obtained in the USA $(\boldsymbol{A}, \boldsymbol{C})$ or EU $(\boldsymbol{B}, \boldsymbol{D})$ from patients with newly diagnosed or relapsed MM were cultured for $48 \mathrm{hr}(\boldsymbol{A}-\boldsymbol{C})$ or $72 \mathrm{hr}(\boldsymbol{D})$ in the absence or presence of compound 18 at the indicated concentration. Samples were then analyzed for viability by flow cytometry, with gating on $\mathrm{CD}_{138^{+}}$or $\mathrm{CD} 138^{-}$cells. Nonmalignant bone marrow aspirates $(\mathrm{n}=3)$ were similarly tested and are depicted for comparison $(\boldsymbol{E})$. Data represent mean \pm SD of triplicate determinations except where triplicates were not possible due to insufficient sample size. Statistical analysis in panels $\mathbf{A}$ and $\mathbf{B}$ was performed by ANOVA. NS, not significant. Further information about age, gender, disease state, cytogenetics, and prior treatments is included in SI Appendix, Fig. S5 $A$.

Fig. 6. IRE1 $\alpha$ kinase inhibition preserves survival and insulin secretion by pancreatic islet 3D microtissues. $(\boldsymbol{A}-\boldsymbol{C})$ Human pancreatic islets were isolated, dissociated into single cells, replated in microtiter wells ( 1000 cells/drop), and allowed to form 3D microtissues of $\sim 120 \mu \mathrm{M}$ in diameter over 7 days using inSphero ${ }^{\mathrm{TM}}$ technology. Microtissues ( $\mathrm{n}=5$ per treatment) were then $(\boldsymbol{A})$ treated for $24 \mathrm{hr}$ with tunicamycin $(5 \mu \mathrm{g} / \mathrm{ml})$ in the absence or presence of compound 18 at the indicated concentrations, lysed, and then analyzed for XBP1s/(XBP1s+XBP1u) mRNA levels by RT-QPCR; or ( $\boldsymbol{B}$ and $\boldsymbol{C}$ ) incubated for 7 days in the absence or presence of $\mathbf{1 8}$ at the indicated concentrations, and then $(\mathbf{B})$ analyzed for cell viability by CellTiterGlo ${ }^{\mathrm{TM}}$ assay; or $(\boldsymbol{C})$ challenged with glucose $(16.7 \mathrm{mM})$ for $1 \mathrm{hr}$ and analyzed for insulin secretion by ELISA. 
A

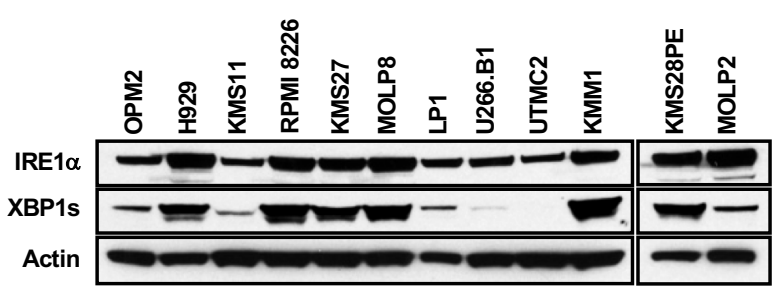

C

KMS11 IRE1 $\alpha$ sh8-9-mCherry

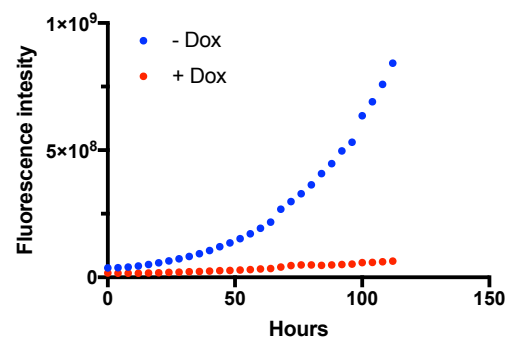

$\mathbf{F}$

KMS11 IRE1 $\alpha$ sh8-9-mCherry

Dox:
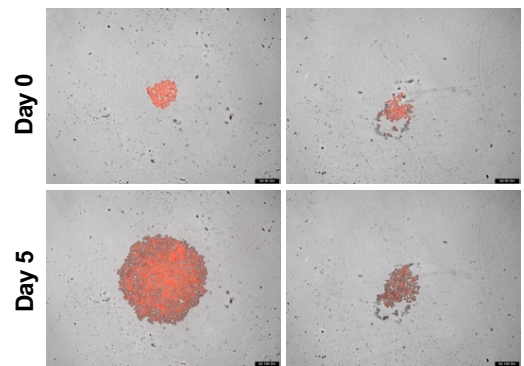

B

\begin{tabular}{|c|c|c|c|}
\hline & $\begin{array}{l}\text { KMS11 } \\
\text { IRE1 } \alpha \\
\text { sh8-9 } \\
\text { mCherry }\end{array}$ & $\begin{array}{c}\text { OPM2 } \\
\text { IRE1 } \alpha \\
\text { sh9 } \\
\text { mCherry }\end{array}$ & $\begin{array}{c}\text { R8226 } \\
\text { IRE1 } \alpha \\
\text { sh7-5 } \\
\text { mCherry }\end{array}$ \\
\hline Dox: & $-\quad+$ & + & - \\
\hline IRE1 $\alpha$ & $\overline{-}$ & - & \\
\hline BP1s & - & & \\
\hline
\end{tabular}

$\mathbf{E}$

OPM2 IRE1 $\alpha$ sh9-mCherry
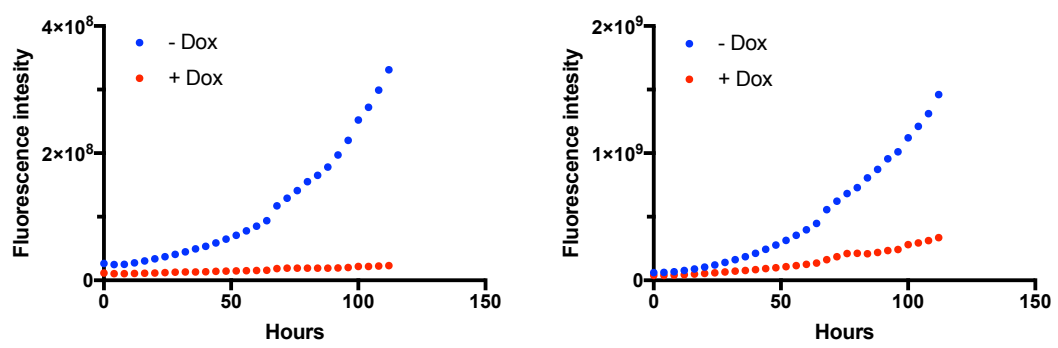

H

RPMI8226 IRE1 $\alpha$ sh7-5mCherry
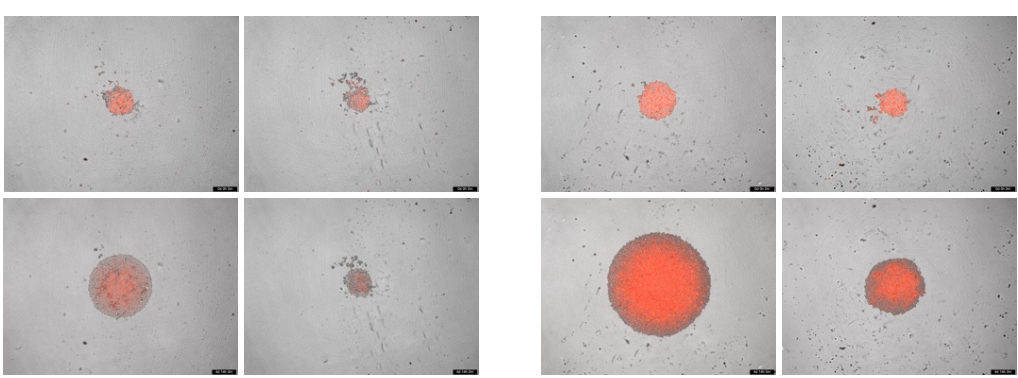

Fig. 1. Expression of IRE1 $\alpha$ in MM cell lines and effect of its depletion on spheroid 3D growth 
A

KMS11

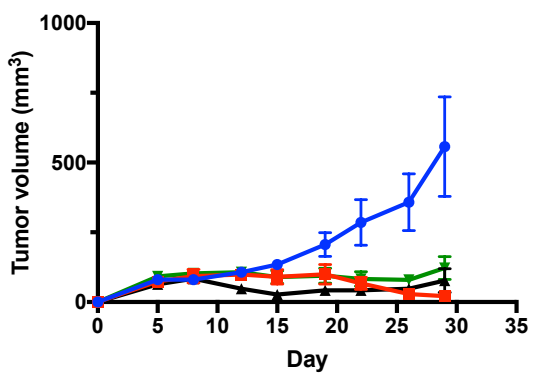

C

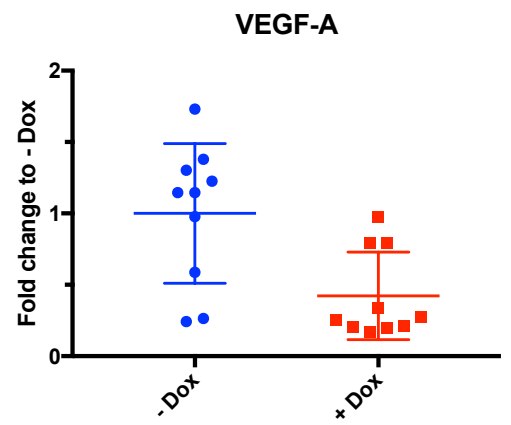

IL-8

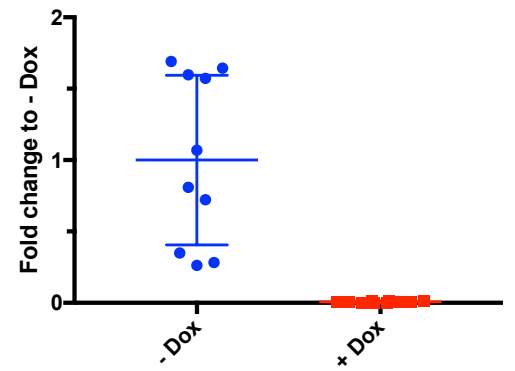

D

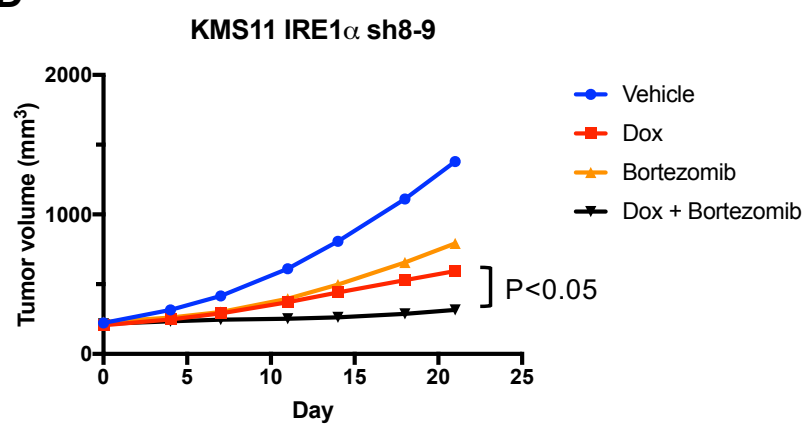

- Parental

- IRE1 KO Cl. 1.1

- IRE1 KO Cl. 2.3

- IRE1 KO Cl. 3.1

B

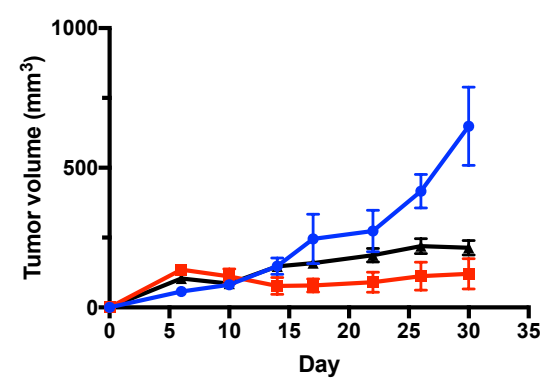

- Parental

- XBP1 KO Cl. 1.8

$\mp$ XBP1 KO Cl. 1.14

IL-1 $\alpha$

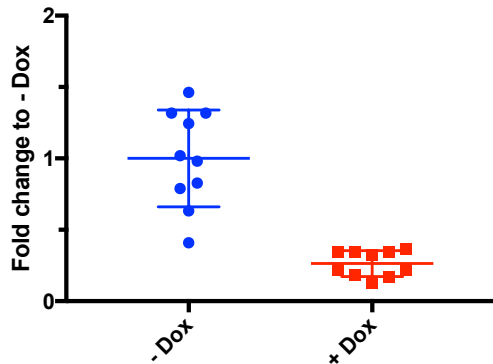

IL-10

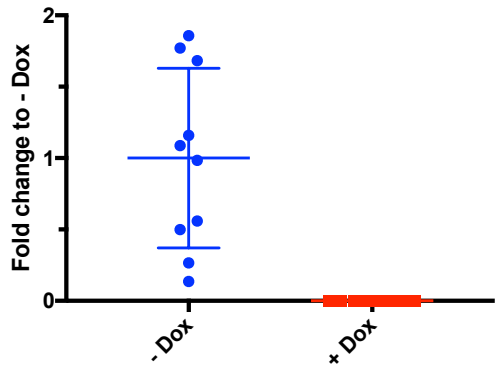

IL-6

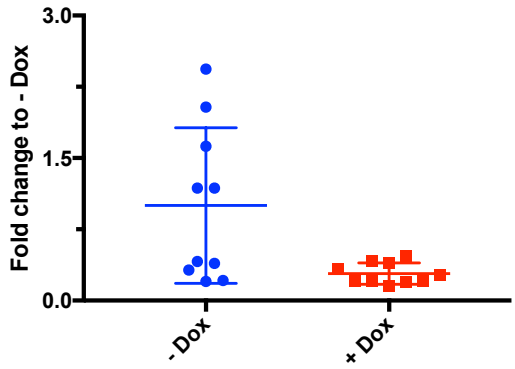

IP-10

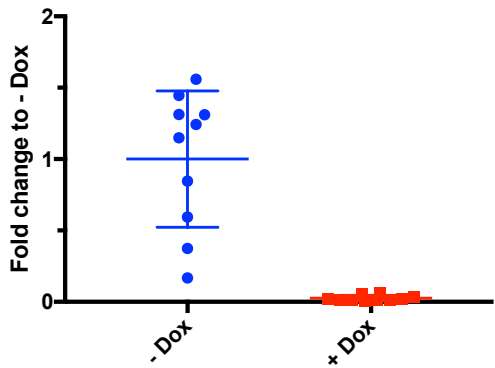

E RPMI8226 IRE1 $\alpha$ sh7-5

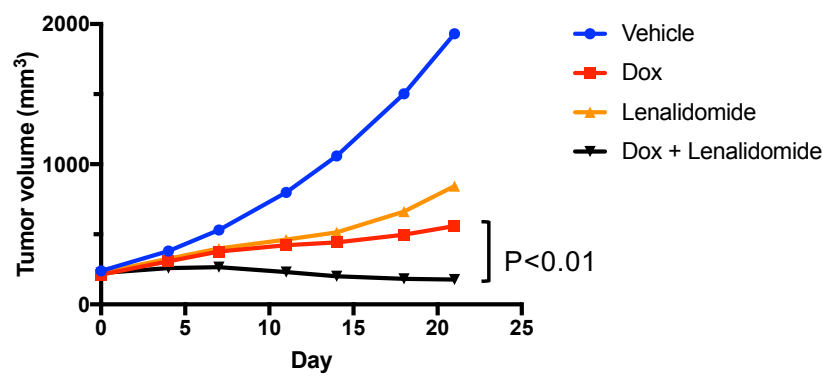

Fig. 2. Genetic disruption of IRE1 $\alpha$ or XBP1 attenuates growth of subcutaneous human MM xenografts in mice 
A

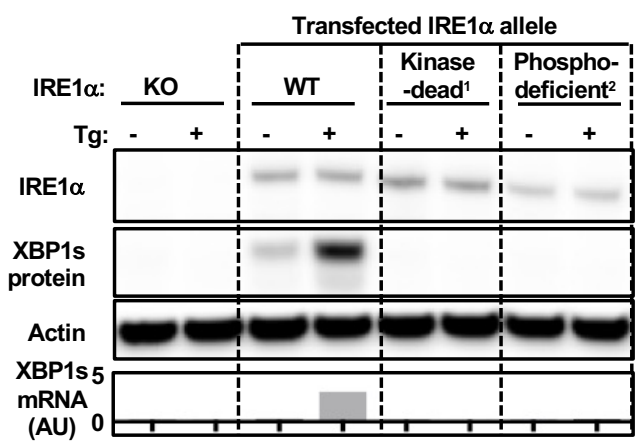

B

\section{Compound 18}

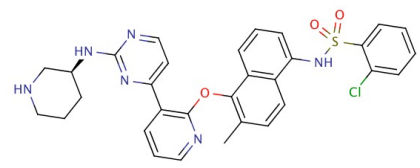

\section{Compound 16}

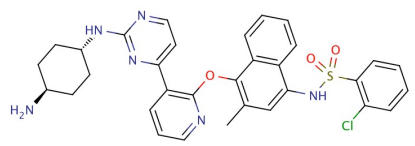

C

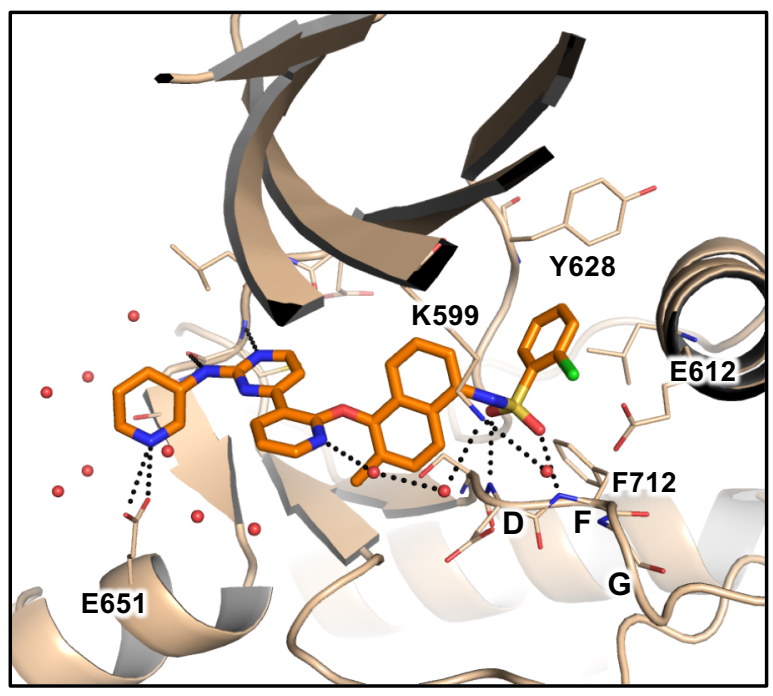

D

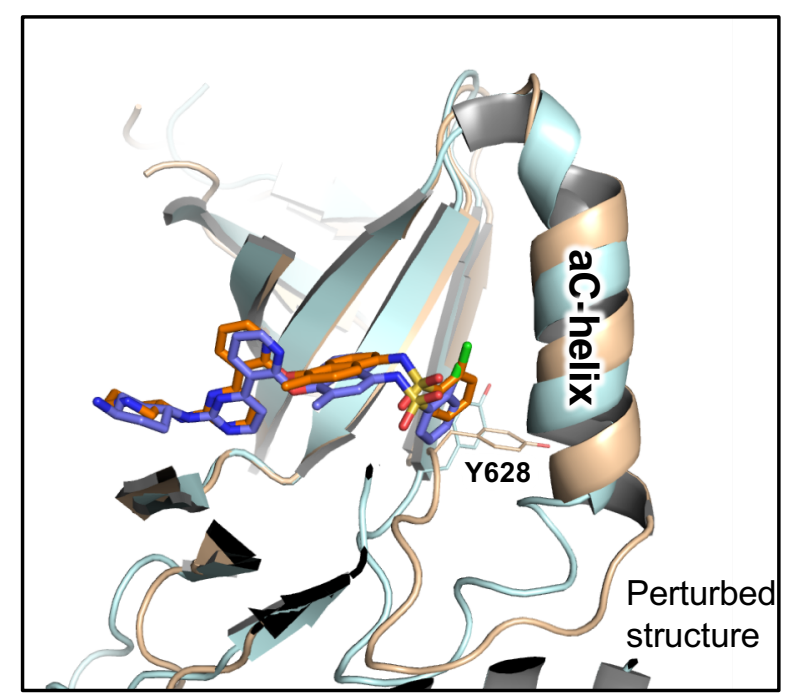

Fig. 3. Importance of IRE $1 \alpha$ kinase in RNase activation and co-crystal structure of IRE $1 \alpha$ with compound 18 as compared to 16 
A

KMS11 IRE1 $\alpha$ sh8-9

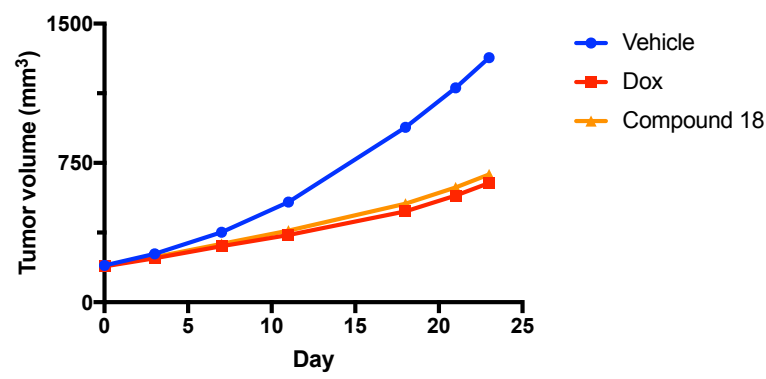

B

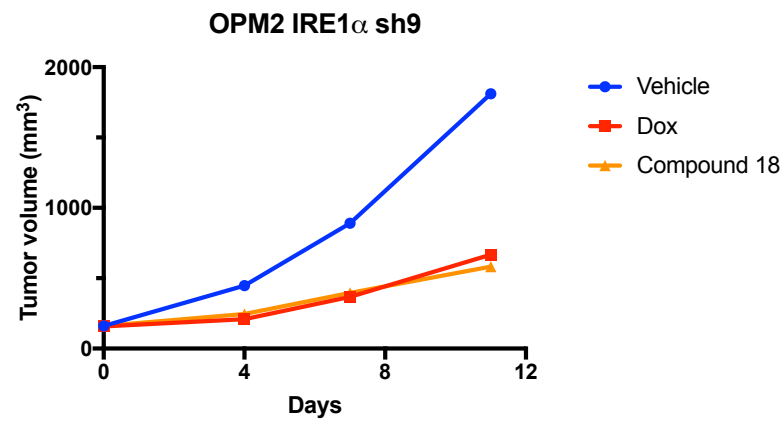

C

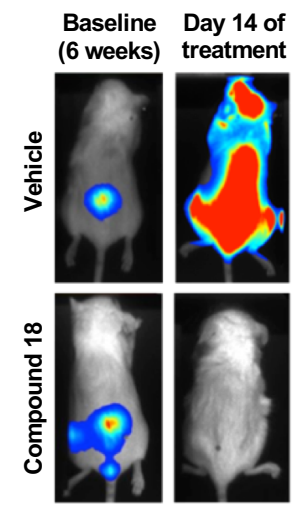

Orthometastatic RPMI8226

xenograft model

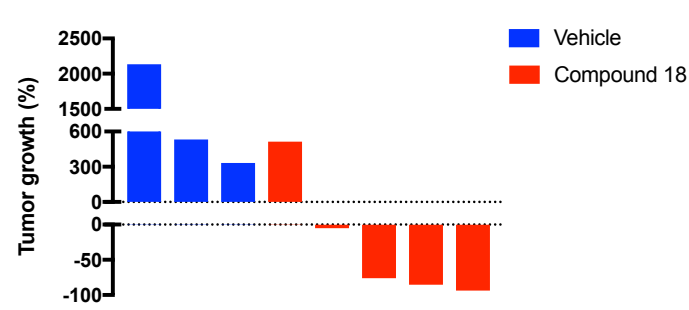

Fig. 4. Small-molecule inhibition of IRE1 $\alpha$ kinase attenuates subcutaneous and orthometastatic growth of human $\mathrm{MM}$ xenografts in mice 
A

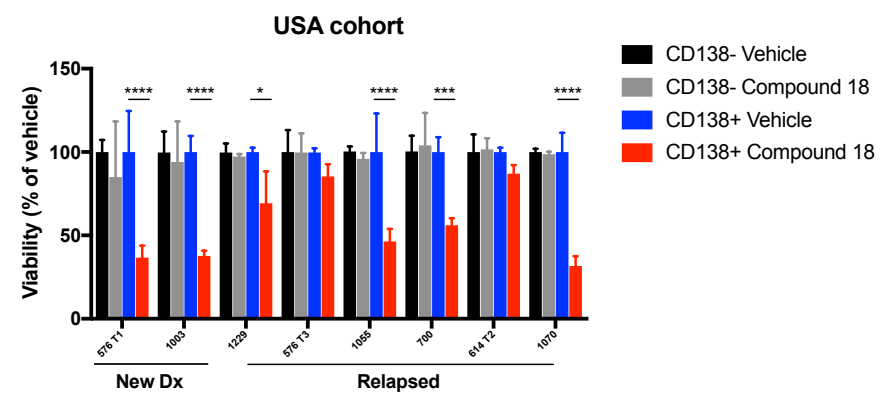

C

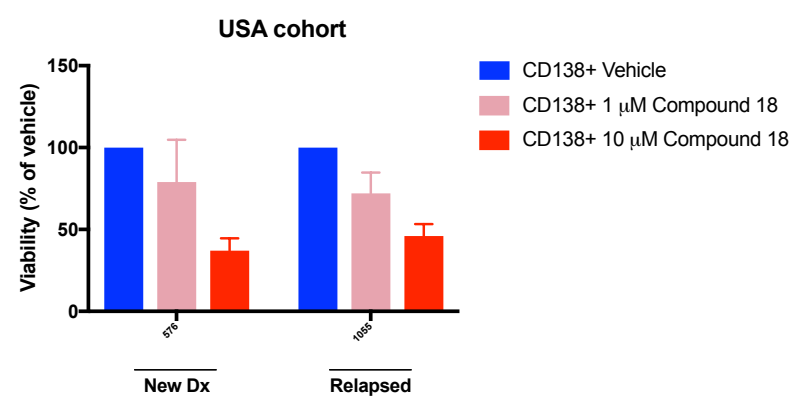

E

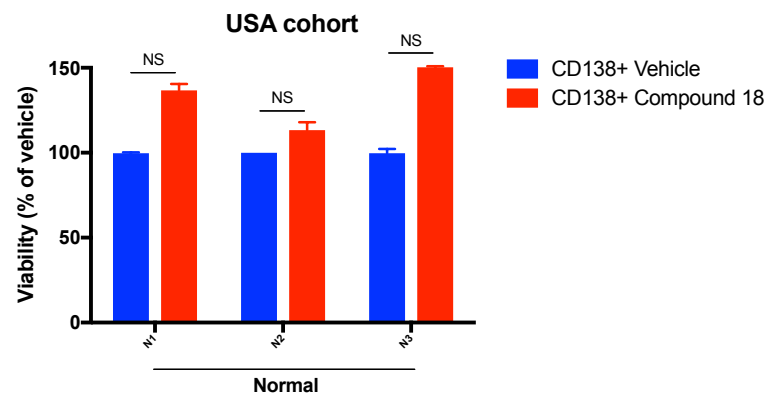

B

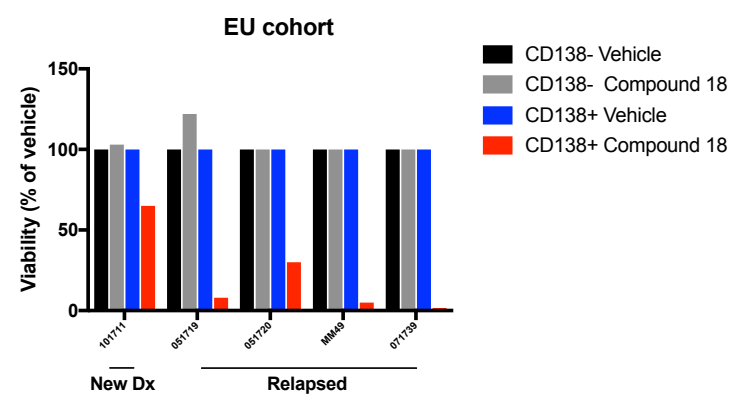

D

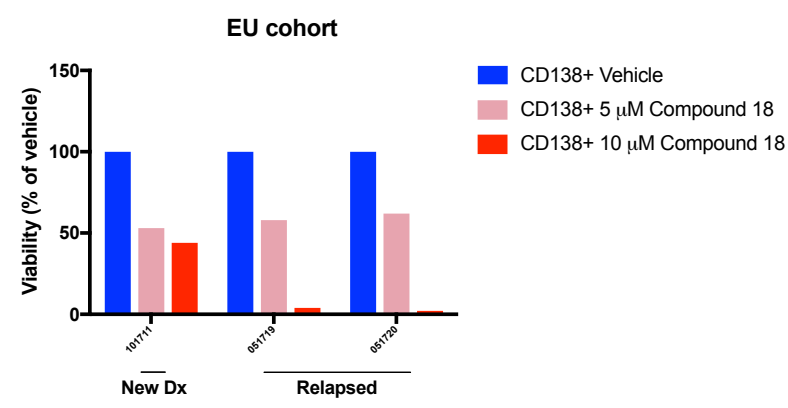

Fig. 5. Small-molecule inhibition of IRE1 $\alpha$ kinase reduces viability of $\mathrm{CD} 138^{+} \mathrm{MM}$ cells in patient-derived samples without disrupting CD138- cells 
A

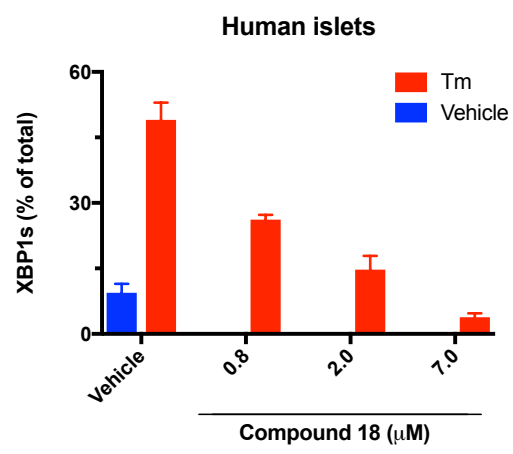

B

Human islets

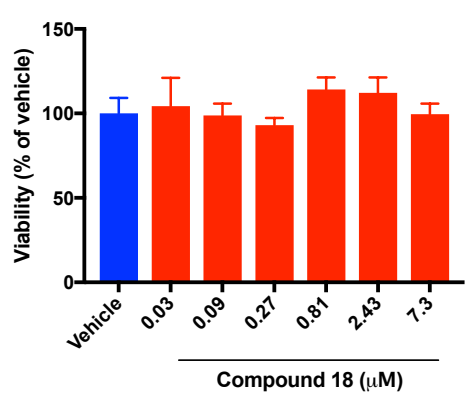

C

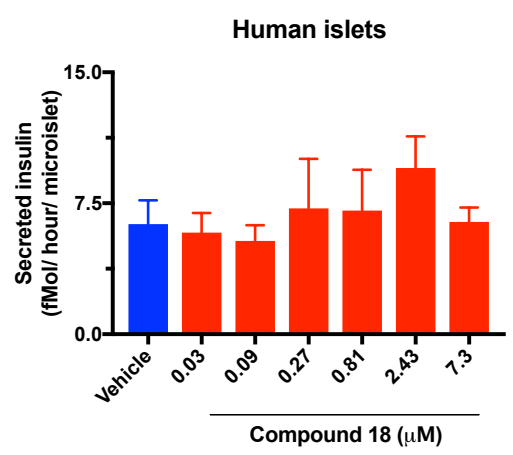

Fig. 6. IRE $1 \alpha$ kinase inhibition preserves survival and insulin secretion by pancreatic islet 3D microtissues 


\section{Supplementary Information for}

\section{Disruption of IRE1 $\alpha$ through its Kinase Domain Attenuates Multiple Myeloma}

Jonathan M Harnoss ${ }^{\mathrm{a}}$, Adrien Le Thomas ${ }^{\mathrm{a}}$, Scot A Marsters ${ }^{\mathrm{a}}$, David A Lawrence ${ }^{\mathrm{a}}$, Min Lu $^{\mathrm{a}, 1}$, Yung-Chia Ariel Chen ${ }^{\mathrm{a}}$, Jing Qing ${ }^{\mathrm{a}}$, Klara Totpal ${ }^{\mathrm{b}}$, David Kan ${ }^{\mathrm{b}}$, Ehud Segal ${ }^{\mathrm{b}}$, Heidi Ackerly Wallweber ${ }^{\mathrm{c}}$, Weiru Wang ${ }^{\mathrm{c}}$, Kevin Clark ${ }^{\mathrm{d}}$, Susan Kaufman ${ }^{\mathrm{d}}$, Maureen Beresini ${ }^{\mathrm{d}}$, Wendy Sandovale ${ }^{\mathrm{e}}$, Maria Lorenzo ${ }^{\mathrm{f}}$, Jiansheng $\mathrm{Wu}^{\mathrm{f}}$, Justin Ly ${ }^{\mathrm{g}}$, Tom De Bruyn ${ }^{\mathrm{g}}$, Amy Heidersbach $^{\mathrm{h}}$, Benjamin Haley ${ }^{\mathrm{h}}$, Alvin Gogineni ${ }^{\mathrm{i}}$, Robby Weimer ${ }^{\mathrm{i}}$, Dong Lee ${ }^{\mathrm{j}, 2}$, MarieGabrielle Braun $^{\mathrm{k}}$, Joachim Rudolph ${ }^{\mathrm{k}}$, Michael J VanWyngarden', Daniel W Sherbenoul, Patricia Gomez-Bougie ${ }^{\mathrm{m}, \mathrm{n}}$, Martine Amiot ${ }^{\mathrm{m}, \mathrm{n}}$, Diego Acosta-Alvear ${ }^{\mathrm{o}, \mathrm{p}, 3}$, Peter Walter ${ }^{\mathrm{o}, \mathrm{p}}$ and Avi Ashkenazi i,4

${ }^{4}$ Corresponding author: Tel: +1 650-225-1853, email: aa@gene.com

\section{This PDF file includes:}

Supplemental Material and Methods Figs. S1 to S6

References for SI reference citations 


\section{Supplemental Material and Methods}

Generation of IRE1 $\alpha$ shRNA-expressing cells. Cells were infected with shRNAs by lentivirus using the pG-GW-pHUSH vector system. Briefly $1 \times 10^{7} 293 \mathrm{~T}$ cells were plated in 6-well dishes, allowed to grow for $24 \mathrm{hr}$ and transfected with lentivirus plasmids using Lipofectamine 2000 (Invitrogen) following the manufacturer's protocol. After $6 \mathrm{hr}$ the media was replaced, and after another $24 \mathrm{hr}$ the virus was harvested from the cells and filtered through a $0.45 \mathrm{~mm}$ tube-top filter. Cleared supernatants containing the viral particles and $8 \mathrm{mg} / \mathrm{ml}$ polybreen were added to the target-cell wells, spun at $1800 \mathrm{rpm}$ for $45 \mathrm{~min}$ at room temperature, and placed back into the incubator. After $48 \mathrm{hr}$ cells were subjected to selection with with puromycin containing media. After 10 passages, cells were tested for virus by Lentivirus X p24 Rapid Titer Kit (Clonetech) then sorted using FACS and RFP+ selection.

IRE1 $\alpha$ shRNA sequences (antisense):

shRNA5:

AGCTTTTCCAAAAAACCAAGATGCTGGAGAGATTTCTCTTGATAATCTCTCCA GCATCTTGGGGG

shRNA7:

AGCTTTTCCAAAAAAAGAACAAGCTCAACTACTTTCTCTTGATAAGTAGTTGA GCTTGTTCTGGG

shRNA8:

AGCTTTTCCAAAAAAGCACGTGAATTGATAGAGATCTCTTGAATCTCTATCAA TTCACGTGCGGG

ShRNA9:

AGCTTTTCCAAAAAAGAGAAGATGATTGCGATGGTCTCTTGAACCATCGCAA TCATCTTCTCGGG

CRISPR/Cas9 knockout of IRE1 $\alpha$ and XBP1 genes. Individual IRE1 $\alpha$ - or XBP1specific sgRNAs were designed using a standard guide scaffold and CRISPR3 $(1,2)$. The gRNAs were cloned into pLKO_AIO_CMV_Cas9_mCherry, enabling co-expression of each sgRNA, Cas9, and an mCherry-based selection marker following transient 
transfection into target cells. A tandem array of XBP1-specific sgRNAs were designed as above and cloned into pLKO_AIO_TAN_PGK_Cas9_Puro, permitting co-expression of two XBP1-targeting sgRNAs, Cas9, and a puromycin selection marker in transfected cells. sgRNA target sequences used in this study:

IRE1 $\alpha$ gRNA1: TCAGGAAGCGTCACTGTGC

IRE1 $\alpha$ gRNA2: GAGGACAGGCTCAATCAAA

IRE1 $\alpha$ gRNA3: TTCTCCCAGATCCTAATGA

\section{XBP1 gRNA1: TTTAGGGGTCCCGTCGGCC}

Transfection was with Lipofectamine 3000 (Invitrogen) according to manufacturer's protocol. At $24 \mathrm{hr}$ after transfection, cells were washed once in PBS and resuspended in PBS media containing 3\% BSA Fraction V. The cell suspension was then filtered through a $35 \mathrm{~mm}$ membrane followed by immediate FACS sorting using the $\mathrm{RFP}^{+}$selection marker. Single cell clones $(n=96)$ were plated and grown. Clones producing colonies were tested for proper IRE $1 \alpha$ or XBP1 disruption by immunoblot.

$\boldsymbol{R} \boldsymbol{T}-\boldsymbol{q P} \boldsymbol{C R}$. RNA was extracted with RNeasy Plus kit (Qiagen). Equal amounts of RNA were reverse transcribed and amplified by RNA-to- $\mathrm{C}_{\mathrm{T}}$ kit (Applied Biosystems). The delta-delta $\mathrm{C}_{\mathrm{T}}$ values were calculated by relating each individual $\mathrm{C}_{\mathrm{T}}$ value to its internal GAPDH control, and then normalizing to the vehicle-treatment control. Taqman primers for GAPDH, XBP1u, XBP1s, and DGAT2 were from Life Technology. RNA was purified from cells using the RNeasy Plus kit (Qiagen). Equal amounts of RNA were reverse transcribed and amplified by RNA-to-CT kit (Applied Biosystems) on the ABI QuantStudio 7 Flex Real-Time PCR System. The delta-delta CT values were calculated by relating each individual CT value to its internal GAPDH control, and then normalized to the vehicle-treatment control.

Taqman primers (Life Technologies):

GAPDH primer: Hs02758991_g1

XBP1u primer: Hs02856596_m1

XBP1s primer: Hs03929085_g1

DGAT2 primer: Hs01045913_m1 
In vitro characterization of small molecule inhibitors. Small molecule potencies were assessed in three assays of IRE1 $\alpha$ function. Compound dilutions covering a range of concentrations from $0.2 \mathrm{nM}$ to $10 \mu \mathrm{M}$ were evaluated to determine $\mathrm{IC}_{50}$ values. Compound binding to the IRE1 $\alpha$ ATP site was assessed through competition with an Alexa647-labeled staurosporine probe for binding to His-tagged IRE1 $\alpha$ (G547-L977 D688N). Probe binding was measured as TR-FRET signal upon energy transfer between the bound probe and anti-His-allophycocyanin bound to the IRE1 $\alpha$. To assess inhibition of RNase activity, compound was mixed with IRE1 $\alpha$ (Q470-L977), and 5'FAMCAUGUCCGCAGCGCAUG-3'BHQ substrate was added. Substrate cleavage was monitored kinetically as an increase in fluorescence. Cellular activity was evaluated via XBP1s-luciferase reporter assay. HEK293T cells stably transfected with the reporter construct were preincubated with compound for $2 \mathrm{hr}$ and then stimulated with $\mathrm{Tg}$ (100 $\mathrm{nM}$ ) for $6 \mathrm{hr}$. IRE1 $\alpha$-mediated cleavage and splicing of the reporter construct led to expression of luciferase, which was detected by the addition of luciferin substrate.

Immunoblot analysis. Cells were lysed or tumor tissue mechanically disrupted in $1 \mathrm{x}$ RIPA buffer (Millipore) containing protease and phosphatase inhibitors (Roche), cleared by centrifugation at 13,000 rpm for $10 \mathrm{~min}$, and analyzed by BCA protein assay (Thermofisher Scientific). Equal protein amounts were loaded, separated by SDS-PAGE, electro-transferred to nitrocellulose membranes using the iBLOT2 system (Invitrogen), and blocked in 5\% nonfat milk solution for 2 hours. Membranes were probed with the following antibodies: IRE1 $\alpha$, GAPDH, $\beta$-actin (Cell Signaling Technology), XBP1s, phosphorylated IRE1 $\alpha($ Genentech(3)). Signal was detected using appropriate horseradish peroxidase (HRP)-conjugated secondary antibodies. All primary antibodies were used at 1:000 dilution and overnight hybridization at $4^{\circ} \mathrm{C}$, followed by a one-hour incubation with horseradish peroxidase (HRP)-conjugated secondary antibodies at 1:10,000 dilution.

Luminex and ELISA analysis. Sera from tumor-bearing mice were analyzed using Luminex Premix Panel I 32-plex (Millipore). IgG and insulin in cell supernatants were 
quantified using human-specific IgG (Abcam) or insulin (Mercodia) Antigen capture enzyme-linked immunosorbent assay (ELISA).

Co-crystallographic studies. The kinase-RNase (KR) domain of hIRE1 $\alpha$, encoding amino acids G547-L977, was expressed as an N-terminal His6-tagged fusion protein in SF9 cells with a TEV protease cleavage site from an intracellular BEVS expression vector.

Cell pellet was resuspended in lysis buffer containing 50 mM HEPES pH 8.0, 300 $\mathrm{mM} \mathrm{NaCl}, 10 \%$ glycerol, $1 \mathrm{mM} \mathrm{MgCl}, 1: 1000$ benzonase, EDTA-free PI tablets (Roche), $1 \mathrm{mM}$ TCEP, and 5mM imidazole. Sample was homogenized, compound $\mathbf{1 8}$ was added to a final concentration of $10 \mu \mathrm{M}$, and incubated at $4^{\circ} \mathrm{C}$ for $30 \mathrm{~min}$. Sample was lysed by sonication, ultracentrifuged at 40,000 rpm for $45 \mathrm{~min}$, and the supernatant filtered through a $0.45 \mu$ Nalgene filter.

Cleared supernatant was batch bound to Ni-NTA Superflow beads (Qiagen) for 1 $\mathrm{hr}$ at $4^{\circ} \mathrm{C}$ with nutation. Beads were washed in lysis buffer supplemented with $25 \mathrm{mM}$ imidazole, followed by protein elution in lysis buffer containing $300 \mathrm{mM}$ imidazole. The eluate was concentrated and loaded onto a Hiload 16/600 Superdex 75 SEC column (GE Healthcare) equilibrated in $25 \mathrm{mM}$ HEPES pH 7.8, $250 \mathrm{mM} \mathrm{NaCl}, 10 \%$ glycerol, $1 \mathrm{mM}$ TCEP (SEC buffer). The monomeric peak was pooled and treated with lambda phosphatase for $1 \mathrm{hr}$ at $37^{\circ} \mathrm{C}$. Dephosphorylation to $0 \mathrm{P}$ was confirmed by mass spectrometry. Sample was incubated with TEV protease overnight at $4^{\circ} \mathrm{C}$ for tag removal. Untagged protein was isolated by passage over a Ni-NTA Superflow gravity column, followed by a wash with SEC buffer supplemented with 40mM imidazole. Flowthrough and wash fractions were pooled, diluted 1:10 in Q buffer (25 mM HEPES pH 7.8 and $1 \mathrm{mM}$ TCEP), and loaded onto a $5 \mathrm{ml}$ prepacked QHP column (GE Healthcare). Protein was eluted over a $50 \mathrm{CV}$ gradient in Q buffers supplemented with $25 \mathrm{mM}$ and $500 \mathrm{mM} \mathrm{NaCl}$. The hIRE1 $\alpha \_\mathrm{KR}+\mathbf{1 8}$ complex peak was isolated and concentrated to 9.4 $\mathrm{mg} / \mathrm{ml}$ for crystallography.

Crystals were generated in hanging drops with mother liquor containing $0.1 \mathrm{M}$ trisodium citrate $\mathrm{pH}$ 5.6, 10\% isopropanol, 10\% PEG4000, and cesium chloride additive at $4{ }^{\circ} \mathrm{C}$. Crystals were cryoprotected in the crystallography buffer supplemented with 
$25 \%$ glycerol and flash frozen in liquid nitrogen. Data collection was done at ALS 5.0.2. Structure was solved to $2.2 \AA$.

In vivo pharmacokinetic analysis. Pharmacokinetic properties of compound 18 were determined in 5 to 6 weeks old female CB-17 SCID mice (Charles River Laboratories) (3 per time-point for once daily (QD) or twice daily (BID) injection). The mice were administered 18 at $30 \mathrm{mg} / \mathrm{kg}$ (formulated in 35\% PEG400 and 10\% EtOH in water) by intraperitoneal injection QD or BID. Food and water were available ad libitum to all animals. Serial blood samples ( $15 \mu \mathrm{L})$ were collected by tail nick at $0.25,0.5,1,2,4,6$, or $8 \mathrm{hr}$ after the administration. Blood samples were diluted with $60 \mu \mathrm{L}$ water containing $1.7 \mathrm{mg} / \mathrm{mL}$ EDTA and kept at $-80^{\circ} \mathrm{C}$ until analysis. Plasma concentrations of $\mathbf{1 8}$ were determined by a non-GLP LC/MS-MS assay.

In vivo studies. Tumor size and body weight were measured twice per week.

Subcutaneous tumor volumes were measured in two dimensions (length and width) using Ultra Cal-IV calipers (model 54-10-111; Fred V. Fowler Co.) and analyzed using Excel, version 11.2 (Microsoft), or Prism 6 (GraphPad Software, Inc.). The tumor volume was calculated with the following formula: tumor size $\left(\mathrm{mm}^{3}\right)=($ longer measurement $\times$ shorter measurement $\left.{ }^{2}\right) \times 0.5$. Animal body weights were measured using an Adventurer Pro AV812 scale (Ohaus Corporation). Percent weight change was calculated using the following formula: group percent weight change $=[($ new weight - initial weight $) /$ initial weight $] \times 100$. To analyze the repeated measurement of tumor volumes from the same animals over time, a mixed modeling approach was used.(4) This approach addresses both repeated measurements and modest dropouts before the end of study. Cubic regression splines were used to fit a nonlinear profile to the time courses of $\log 2$ tumor volume in each group. Fitting was done via a linear mixed-effects model, using the package "nlme" (version 3.1-108) in R version 2.15.2 (R Development Core Team 2008; R Foundation for Statistical Computing; Vienna, Austria). Tumor growth inhibition (TGI) as a percentage of vehicle was calculated as the percentage of the area under the fitted tumor volume-time curve (AUC) per day for each treatment group in relation to the vehicle control using the following formula: $\% \mathrm{TGI}=\% \mathrm{TGI}=\left(1-\left[(\mathrm{AUC} / \mathrm{Day})_{\text {Treatment }} \div\right.\right.$ 
(AUC/Day)vehicle]) X 100. When mice reached endpoint criteria (see below) or on the last treatment day, mice were euthanized by cervical dislocation and subcutaneous xenografts harvested for immunoblot analysis.

Animals in all studies were humanely euthanized according to the following criteria: clinical signs of persistent distress or pain, significant body-weight loss $(>20 \%)$, tumor size exceeding $2500 \mathrm{~mm}^{3}$, or when tumors ulcerated. Maximum tumor size permitted by the Institutional Animal Care and Use Committee (IACUC) is $3000 \mathrm{~mm}^{3}$ and in none of the experiments was this limit exceeded. 

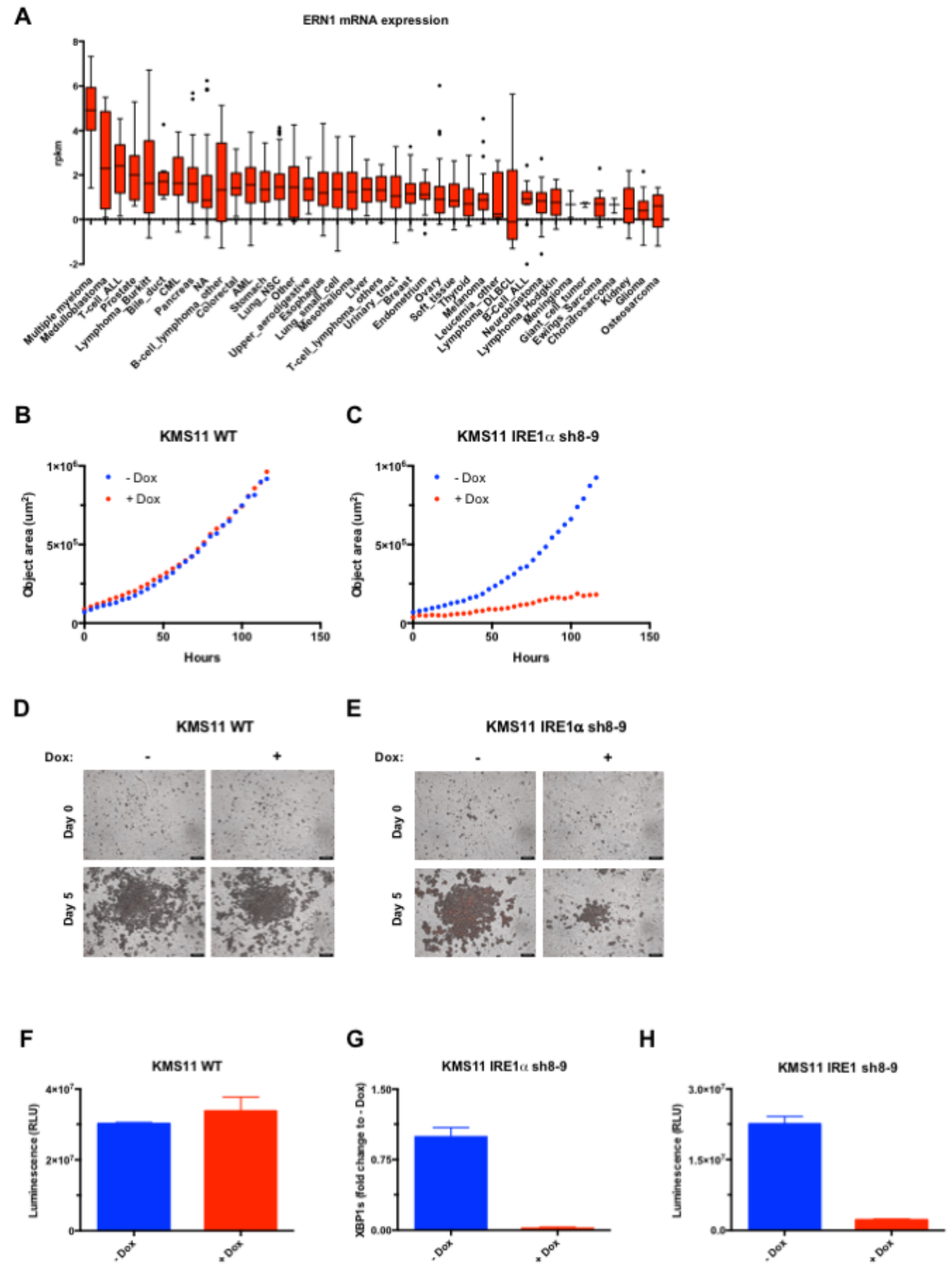

Fig. S1. Expression of IRE1 $\alpha$ in cancer cell lines and effect of its shRNA-based depletion on 3D spheroid growth of MM cells. $(A)$ The cancer cell line encyclopedia (CCLE) dataset, which comprises RNAseq-based analysis of human cancer cell lines 
including 29 MM lines (Broad Institute, Cambridge, MA, USA)

(https://portals.broadinstitute.org/ccle/page?gene=ERN1) was queried for expression of IRE1 $\alpha$ (ERN1). ( $\boldsymbol{B}$ and $\boldsymbol{C}$ ) Non-transfected KMS11 cells (WT) or cells stably transfected with plasmids encoding Dox-inducible shRNAs against IRE1 $\alpha$ were treated with Dox $(0.5 \mu \mathrm{g} / \mathrm{ml})$ for 3 days, seeded on Matrigel, allowed to grow as multiple 3D-spheroids, and analyzed over 5 days in an Incucyte ${ }^{\mathrm{TM}}$ instrument. $(\boldsymbol{F}-\boldsymbol{H})$ Cells were treated as in $\boldsymbol{B}$ and $\boldsymbol{C}$ and analyzed by CellTiterGlo ${ }^{\circledR}$ assay to determine viability $(\boldsymbol{F}-\boldsymbol{H})$ or RT-QPCR to determine XBP1s mRNA levels $(\boldsymbol{G})$. 
A

$\frac{\text { KMS11 shIRE1 } \alpha \text { 8-9 }}{\text { Parental Cl. 1.1 Cl. 2.3 Cl. 3.1 }}$

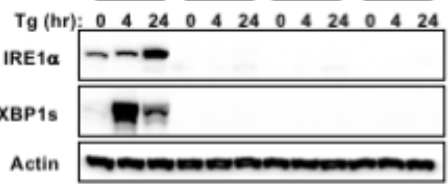

D

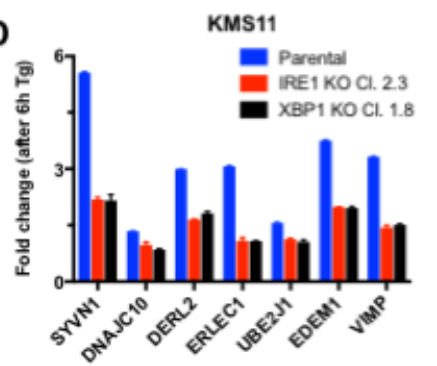

$\mathbf{F}$
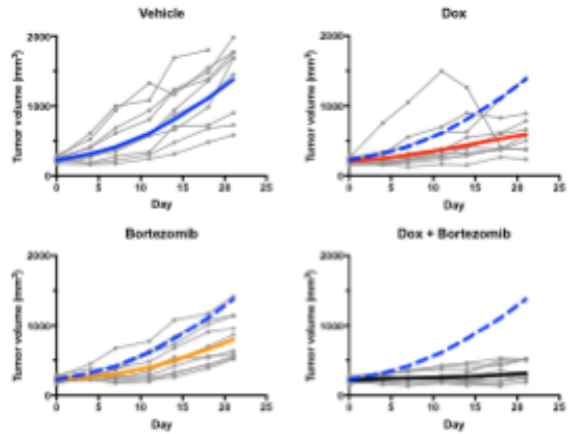

\begin{tabular}{|c|c|c|c|c|}
\hline & $\begin{array}{c}\text { Treatment } \\
\text { group }\end{array}$ & $\begin{array}{c}\text { N of animals } \\
\text { day o/ last } \\
\text { day }\end{array}$ & $\begin{array}{c}\text { AUC/ day } \% \\
\text { TGI mean } \\
\text { (range) }\end{array}$ & $\begin{array}{c}\text { AUC/ day } \\
\text { mean } \\
\text { (range) }\end{array}$ \\
\hline 1 & $\begin{array}{l}\text { Vehicle } \\
\text { (5\% sucrose) }\end{array}$ & $10 / 9$ & $0(0,0)$ & $\begin{array}{c}431 \\
(281,671)\end{array}$ \\
\hline 2 & $\begin{array}{l}\text { Doxycyline } \\
(0.5 \text { mg/mL, PO) }\end{array}$ & $10 / 9$ & $61(24,81)$ & $\begin{array}{c}167 \\
(91,289)\end{array}$ \\
\hline 3 & $\begin{array}{l}\text { Bortezomib } \\
(0.75 \text { mgikg IV } \\
\text { BIW })\end{array}$ & $10 / 10$ & $54(7,79)$ & $\begin{array}{c}197 \\
(108,328)\end{array}$ \\
\hline 4 & $\begin{array}{l}\text { Bortezomib } \\
(0.75 \text { mg/kg IP } \\
\text { BiW }+ \\
\text { Doxycyline } \\
(0.5 \text { mg/mL, PO) }\end{array}$ & $10 / 9$ & $91(73,102)$ & $\begin{array}{c}40 \\
(-8,104)\end{array}$ \\
\hline
\end{tabular}

H
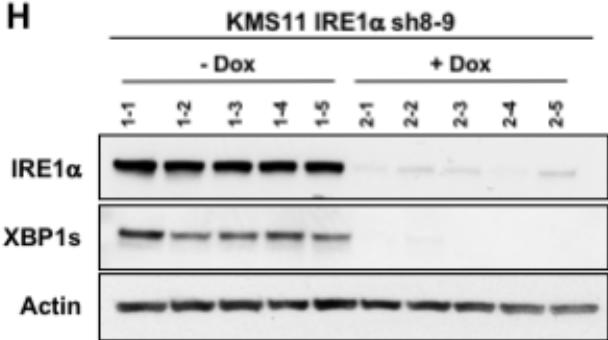

B

E
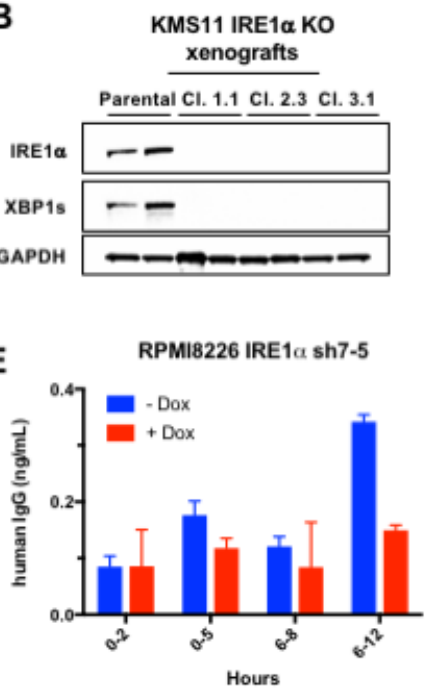

G
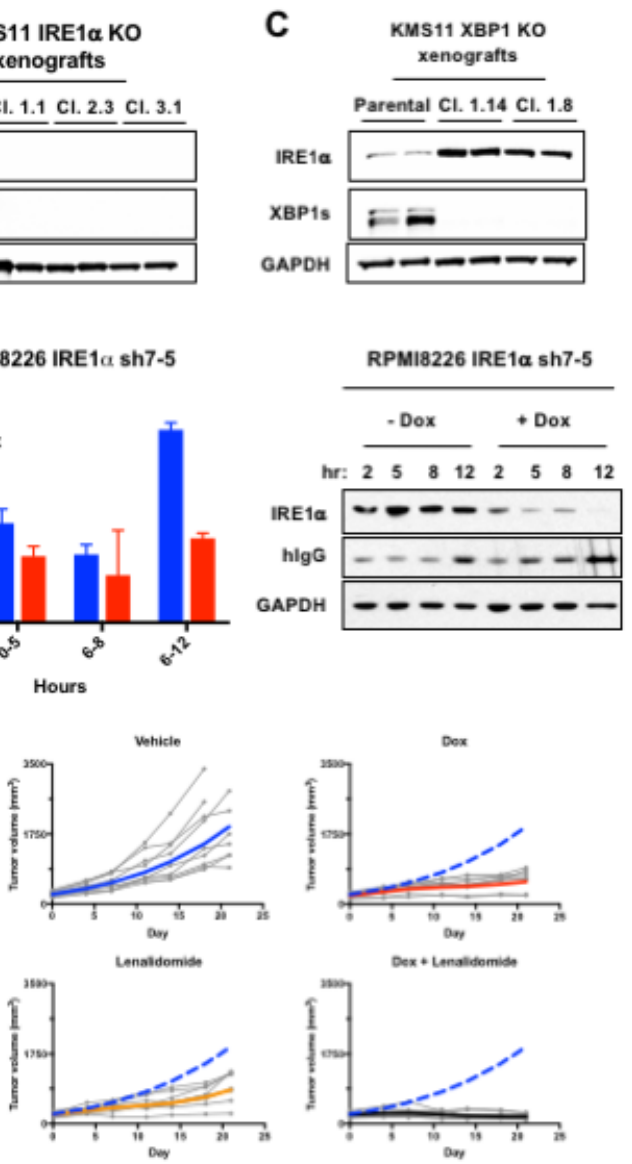

\begin{tabular}{|c|c|c|c|c|}
\hline & $\begin{array}{l}\text { Treatment } \\
\text { group }\end{array}$ & $\begin{array}{c}\text { Nof animals } \\
\text { day } 0 / \text { last } \\
\text { day }\end{array}$ & $\begin{array}{c}\text { AUC/ day \% } \\
\text { TGI mean } \\
\text { (range) }\end{array}$ & $\begin{array}{c}\text { AUC/ day } \\
\text { mean } \\
\text { (range) }\end{array}$ \\
\hline 1 & $\begin{array}{l}\text { Vehicle } \\
\text { (5\% sucrose) }\end{array}$ & $9 / 7$ & $0(0,0)$ & $\begin{array}{c}619 \\
(392,903)\end{array}$ \\
\hline 2 & $\begin{array}{l}\text { Doxycyline } \\
(0.5 \mathrm{mg} / \mathrm{mL}, \mathrm{PO})\end{array}$ & $8 / 8$ & $70(42,84)$ & $\begin{array}{c}187 \\
(109,299)\end{array}$ \\
\hline 3 & $\begin{array}{l}\text { Revlimid } \\
(50 \mathrm{mg} / \mathrm{kg} \text { IP } \\
0 \mathrm{QD} 5)^{2}\end{array}$ & $8 / 8$ & $61(24,78)$ & $\begin{array}{c}243 \\
(140,384)\end{array}$ \\
\hline 4 & $\begin{array}{l}\text { Revlimid } \\
(50 \mathrm{mg} / \mathrm{kg} \text { IP } \\
\mathrm{ODx} 5)^{+}+ \\
\text {Doxycyline } \\
(0.5 \mathrm{mg} / \mathrm{mL}, \mathrm{PO})\end{array}$ & $8 / 8$ & $100(92,107)$ & $\begin{array}{c}0 \\
(-41,45)\end{array}$ \\
\hline
\end{tabular}

I

RPMI8226 IRE $1 \alpha \operatorname{sh} 7-5$

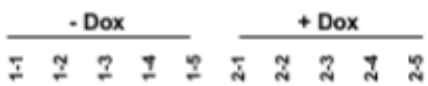

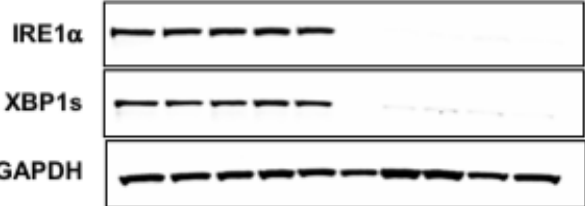

Fig. S2. Genetic disruption of IRE1 $\alpha$ attenuates secretory function and growth of subcutaneous human MM tumor xenografts in mice. $(\boldsymbol{A})$ Parental and IRE1 $\alpha$ KO 
KMS11 cells were treated with $\mathrm{Tg}(\mathrm{Tg}, 100 \mathrm{nM})$ for the indicated time and analyzed by IB for expression of IRE1 $\alpha$ and XBP1s protein. ( $\boldsymbol{B}$ and $\boldsymbol{C}$ ) IB analysis to confirm depletion of IRE1 $\alpha$ and XBP1s in corresponding WT and KO KMS11 tumor xenografts. (D) IRE1 $\alpha$ WT and KO cells were treated with Tg (100 nM) for $8 \mathrm{hr}$ and analyzed by RNAseq. Fold-change in mRNA expression is shown for the indicated components of the ERAD machinery. (E) KMS11 cells stably transfected with a plasmid encoding shRNAs against IRE1 $\alpha$ were incubated in the absence or presence of Dox $(1 \mu \mathrm{g} / \mathrm{ml})$ for up to 12 days. Levels of human IgG were analyzed in cell supernatants by ELISA (left-hand panel) or in cell lysates by IB (right-hand panel). ( $\boldsymbol{F}$ and $\boldsymbol{G})$ Tumor growth trajectories of individual animals, corresponding to the mean tumor volumes depicted in Fig. $2 D(F)$ and Fig. $2 \boldsymbol{E}(\boldsymbol{G})$. ( $\boldsymbol{H}$ and $\boldsymbol{I}$ ) IB analysis to confirming Dox-induced shRNA depletion of IRE1 $\alpha$ and XBP1s in individual tumor xenografts. 
A

\begin{tabular}{|l|c|c|}
\hline Compound & 18 & 16 \\
\hline IRE1 FRET assay IC50 (nM) & 3.1 & 3.7 \\
\hline IRE1 RNase assay IC50 (nM) & 3.3 & 4.2 \\
\hline XBP1 reporter cell assay IC50 (nM) & 35 & 57 \\
\hline $\begin{array}{l}\text { KinomeScan } \\
\text { Kinases Invitrogen assay at } 1 \mu \mathrm{M} \text { > 90\% off-target inhibition } \\
\text { Kinases with > 70-90\% off-target inhibition }\end{array}$ & $\begin{array}{l}1 / 220 \\
0 / 220\end{array}$ & $\begin{array}{l}3 / 220 \\
5 / 220\end{array}$ \\
\hline Plasma protein binding (human, mouse) (\%) & $99.4,99.4$ & $99.2,99.7$ \\
\hline
\end{tabular}

B

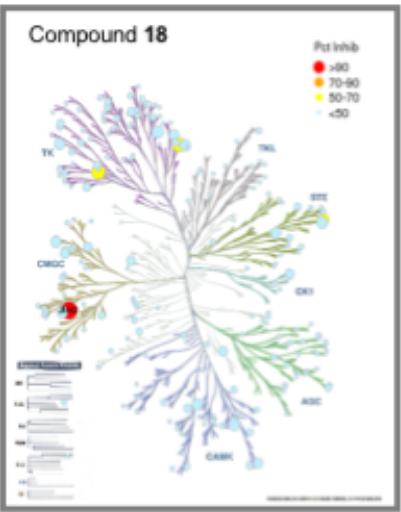

D

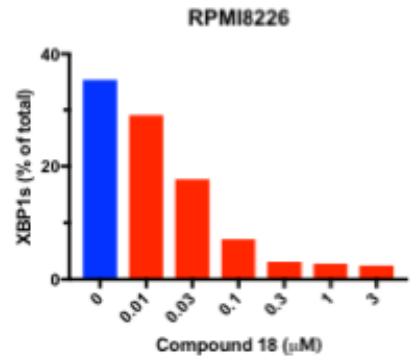

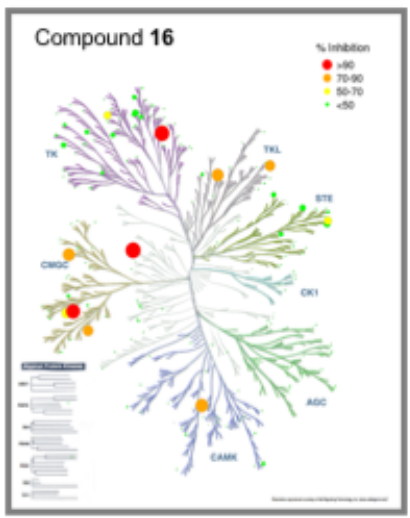

E

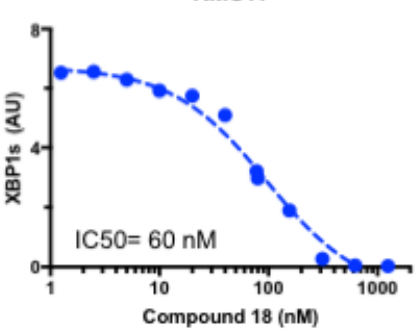

C

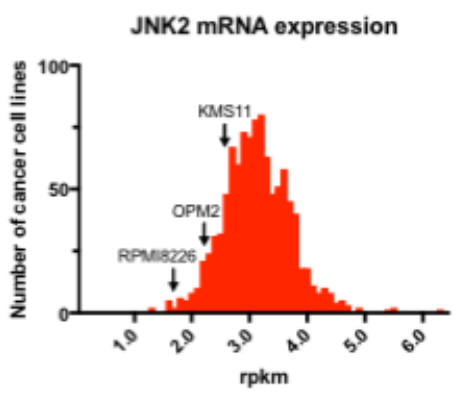

$\mathbf{F}$

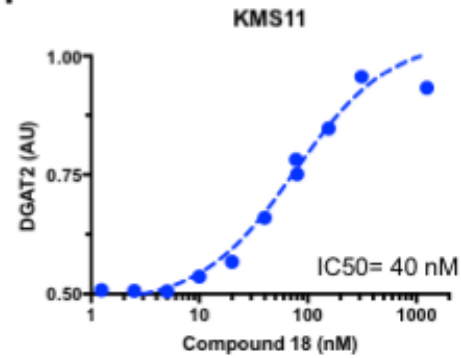

G

\begin{tabular}{|c|c|}
\hline & Compound $18+$ IRE $1 \alpha$ KR \\
\hline PDB code & $\begin{array}{c}\text { TBD } \\
\text { 2016_09_14_ALS_502 } \\
\text { 22744 } \\
\text { _G02968219_KR_WT }\end{array}$ \\
\hline Space group & $P 2,2,2$, \\
\hline Unit cell & $\begin{array}{c}a=67.1 \mathrm{~A}, b=84.7 \mathrm{~A}, \\
c=175.5 \mathrm{~A}, \\
a=\beta=\gamma=90^{\circ}\end{array}$ \\
\hline Resolution & $2.20 \mathrm{~A}$ \\
\hline $\begin{array}{c}\text { Total measured } \\
\text { reflections }\end{array}$ & $367185(3613)^{1}$ \\
\hline Completeness (\%) & $100(100)$ \\
\hline Redundancy & $7.1(7.3)$ \\
\hline
\end{tabular}

\begin{tabular}{|c|c|}
\hline & Compound $18+$ IRE1 $\alpha$ KR \\
\hline $\mathrm{V} / \sigma$ & $7.6(2.8)$ \\
\hline Rsym² & $0.158(0.670)$ \\
\hline Resolution range & $50-2.20 \mathrm{~A}$ \\
\hline Rcryst $^{3} /$ Rfree $^{4}$ & $0.220 / 0.274$ \\
\hline Non-hydrogen atoms & 7116 \\
\hline Water molecules & 589 \\
\hline Average $\mathrm{B}$ & $26.4 \mathrm{~A}^{2}$ \\
\hline r.m.s.d. bond lengths & $0.006 \mathrm{~A}$ \\
\hline r.m.s.d. angles & $0.925^{\circ}$ \\
\hline Ramachandran & $0.908 / 0.088 / 0.001 / 0.003$ \\
\hline
\end{tabular}

Figure S3. Biochemical characterization of compounds 18 and 16. $(A)$ Biochemical properties and kinase selectivity of compound 18 and 16. Kinase inhibition was determined by competition for binding of a staurosporine-based probe to the kinase 
pocket of a recombinant IRE1 $\alpha$ protein comprising the kinase and endoribunuclease moieties. RNase activity of the recombinant protein was measured by cleavage of an XBP1s-based stem-loop structured RNA substrate as previously described (5). XBP1s cell reporter assay was performed as previously described $(3,5)$ (see Methods). Kinaseselectivity analysis against a panel of 220 kinases was performed at a compound concentration of $1 \mu \mathrm{M}$ by KinomeScan ${ }^{\mathrm{TM}}$. (B) Schematic representation of the kinase interactions of 18 and 16. Size and color of circles are related to interaction strength, as indicated in the top right inset. $(\boldsymbol{C})$ Histogram of relative JNK2 mRNA expression in 1019 cancer cell lines in the CCLE dataset (Broad Institute, Cambridge, MA, USA). (D) RPMI8226 cells were incubated in the absence or presence of serial dilutions of $\mathbf{1 8}$ or $\mathbf{1 6}$, for $8 \mathrm{hr}$ and analyzed for constitutive XBP1s and XBP1u mRNA levels by RT-QPCR (\%XBP1s mRNA is the ratio of XBP1s mRNA/(XBP1s mRNA+XBP1u mRNA). ( $\boldsymbol{E}$ and F) KMS11 cells were incubated for $8 \mathrm{hr}$ with $\mathrm{Tg}(100 \mathrm{nM})$ in the absence or presence of 18 serial dilutions and analyzed by RT-QPCR for mRNA levels of XBP1s $(\boldsymbol{G})$ or the RIDD target DGAT2 $(\boldsymbol{F})$. Data in $\boldsymbol{D}-\boldsymbol{F}$ are shown as the mean of triplicate determinations. $(\boldsymbol{G})$ Crystallographic statistics for the structure of $\mathbf{1 8}$ with IRE1 $\alpha$. 
A

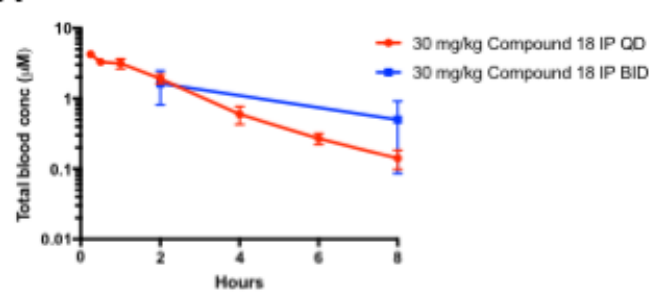

C

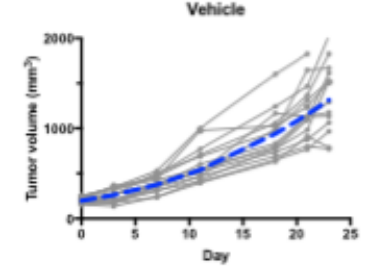

B

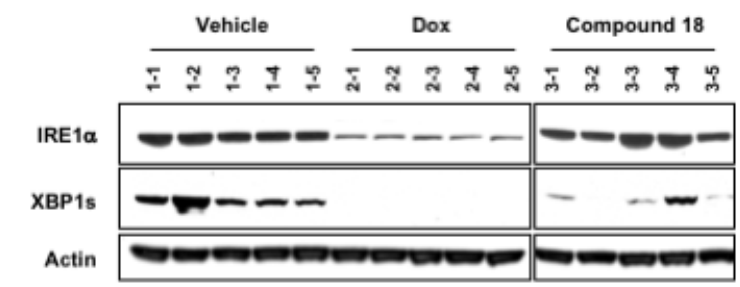

Dox

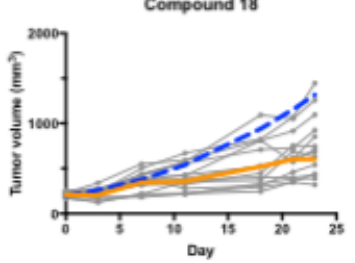

\begin{tabular}{|c|l|c|c|c|}
\hline & Treatment group & $\begin{array}{c}\text { N of } \\
\text { animals } \\
\text { day o/ last } \\
\text { day }\end{array}$ & $\begin{array}{c}\text { AUC/ day \% } \\
\text { TGl mean } \\
\text { (range) }\end{array}$ & $\begin{array}{c}\text { AUC/ day } \\
\text { mean } \\
\text { (range) }\end{array}$ \\
\hline 1 & $\begin{array}{l}\text { Vehicle } \\
\text { (5\% sucrose) }\end{array}$ & $15 / 14$ & $0(0,0)$ & $\begin{array}{c}427 \\
(314,573)\end{array}$ \\
\hline 2 & $\begin{array}{l}\text { Doxycyline } \\
(0.5 \text { mg/mL, PO) }\end{array}$ & $15 / 15$ & $56(31,74)$ & $\begin{array}{c}187 \\
(126,266)\end{array}$ \\
\hline 3 & $\begin{array}{l}\text { Compound 18 } \\
(30 \mathrm{mg} / \mathrm{kg} \text { IP, BID) }\end{array}$ & $15 / 14$ & $51(22,70)$ & $\begin{array}{c}209 \\
(142,290)\end{array}$ \\
\hline
\end{tabular}

D

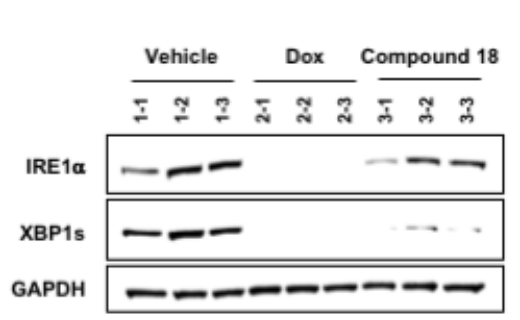

E
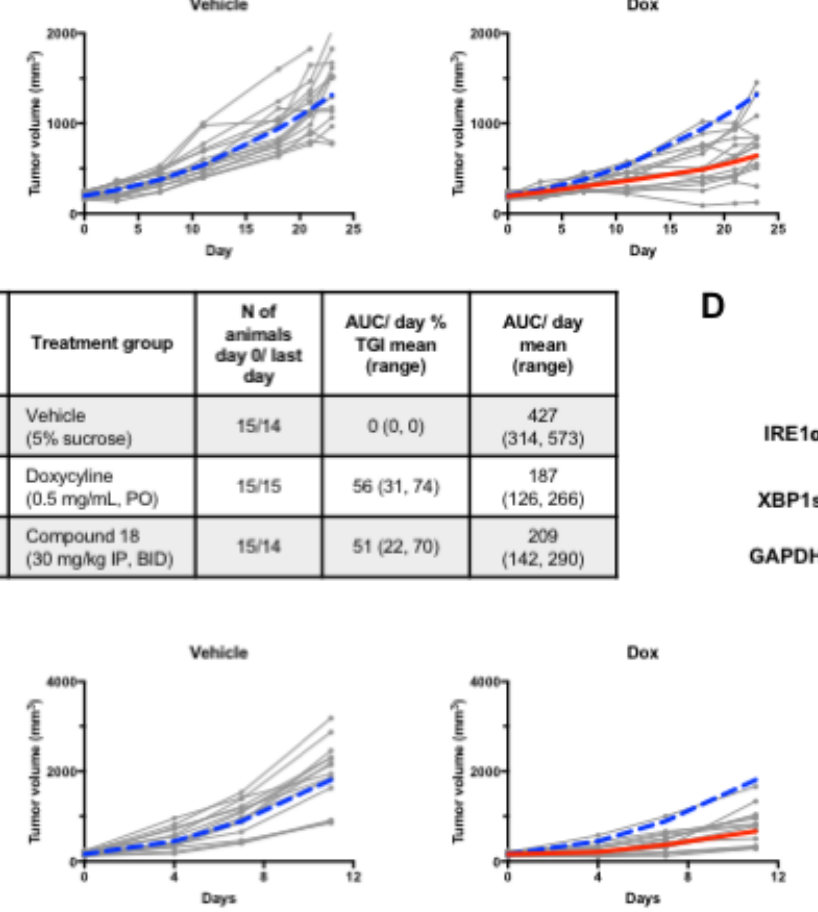

Dox
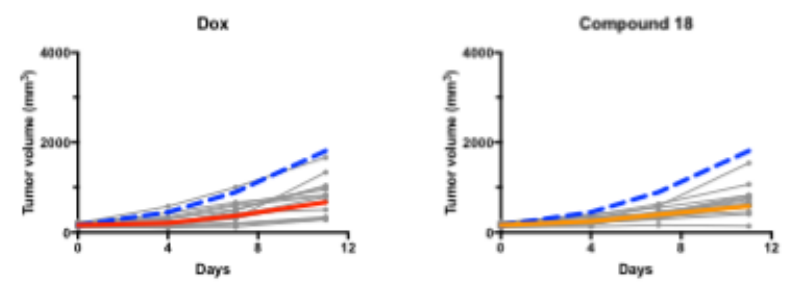

\begin{tabular}{|c|l|c|c|c|}
\hline & Treatment group & $\begin{array}{c}\text { N of } \\
\text { animals } \\
\text { day o/ last } \\
\text { day }\end{array}$ & $\begin{array}{c}\text { AUC/ day \% } \\
\text { TGI mean } \\
\text { (range) }\end{array}$ & $\begin{array}{c}\text { AUC/ day } \\
\text { mean } \\
\text { (range) }\end{array}$ \\
\hline 1 & $\begin{array}{l}\text { Vehicle } \\
\text { (5\% sucrose) }\end{array}$ & $14 / 14$ & $0(0,0)$ & $\begin{array}{c}583 \\
(418,804)\end{array}$ \\
\hline 2 & $\begin{array}{l}\text { Doxycyline } \\
(0.5 \text { mglmL, PO) }\end{array}$ & $14 / 15$ & $72(50,84)$ & $\begin{array}{c}165 \\
(103,254)\end{array}$ \\
\hline 3 & $\begin{array}{l}\text { Compound 18 } \\
(30 \text { mg/kg IP, QD) }\end{array}$ & $14 / 14$ & $70(50,84)$ & $\begin{array}{c}172 \\
(109,225)\end{array}$ \\
\hline
\end{tabular}

F
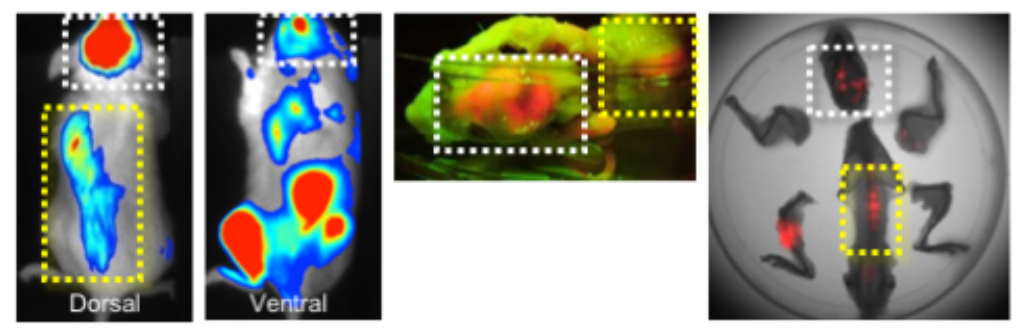

Fig. S4. Small-molecule inhibition of IRE1 $\alpha$ kinase attenuates XBP1s production and subcutaneous growth of human MM xenografts in mice. $(A)$ C.B17-SCID mice 
bearing subcutaneous KMS11 tumor xenografts ( 3 per group) were treated either daily (QD) or twice per day (BID) intraperitoneally with 18 (30 mg/kg) over 4 days. Plasma was collected at the indicated time after the last dose and compound concentrations were determined by liquid chromatography and mass spectrometry. (B) Confirmation of XBP1s depletion in tumor xenografts sampled from individual mice depicted in Fig. $4 \boldsymbol{A}$. (C) Tumor growth trajectories of individual animals, corresponding to the mean tumor volumes depicted in Fig. 4A. (D) Confirmation of XBP1s depletion in tumor xenografts sampled from individual mice depicted in Fig. 4B. (E) Tumor growth trajectories of individual animals, corresponding to the mean tumor volumes depicted in Fig. $4 B$. (F) RPMI8226 cells expressing plasmids encoding mCherry and luciferase were intravenously injected via the tail vein. Multifocal orthometastatic growth in the bone marrow (with typical skeletal lesions in the skull (white dashed box) and spine (yellow dashed box)) was confirmed by live bioluminescence (left-hand panels), post-mortal fluorescence imaging (middle panel), or fluorescence co-registered with X-ray imaging (right-hand panel) within same animals. 
A

\begin{tabular}{|c|c|c|c|c|c|c|c|c|}
\hline Cohort & Patient \# & $\begin{array}{l}\text { Age, } \\
\text { Sex }\end{array}$ & $\begin{array}{c}\text { Disease } \\
\text { Type }\end{array}$ & Disease State & $\begin{array}{l}\mathrm{BM} \\
\mathrm{MM} \\
(\%)\end{array}$ & FISH/QPCR & $\begin{array}{l}\text { Prior } \\
\text { Lines }\end{array}$ & $\begin{array}{c}\text { Prior Treatments } \\
\text { Include }\end{array}$ \\
\hline \multirow[t]{8}{*}{ USA } & $576 \mathrm{~T} 1$ & $45, F$ & MM & Diagnosis & $40-50$ & $\begin{array}{l}\text { Hyperdiplpoid } \\
13 \mathrm{q}-; \mathrm{IgH+}\end{array}$ & 0 & None \\
\hline & 1003 & $60, F$ & MM & Diagnosis & $25-30$ & $1 q^{+}, 13 q-, \mathrm{gH}+$ & 0 & None \\
\hline & 1229 & $52, \mathrm{M}$ & MM & Diagnosis & 40 & N/A & 0 & None \\
\hline & $576 \mathrm{~T} 3$ & $47, F$ & MM & Relapsed & 40 & Hyperdiploid, 13q- & 1 & $\begin{array}{c}\text { Cyclophosphamide } \\
\text {, bortezomib, } \\
\text { dexamethasone; } \\
\text { autologous stem } \\
\text { cell transplant with } \\
\text { melphalan; } \\
\text { observation } \\
\end{array}$ \\
\hline & 1055 & $61, M$ & MM & Relapsed & $10-15$ & $t(X ; 4)+$ & 1 & $\begin{array}{l}\text { Bortezomib, } \\
\text { dexamethasone }\end{array}$ \\
\hline & 70002 & $67, \mathrm{M}$ & MM & Relapsed & 30 & $\mathrm{t}(11 ; 14)+; 1 \mathrm{q}^{+}$ & 2 & $\begin{array}{l}\text { Cyclophosphamide } \\
\text {, bortezomib, } \\
\text { dexamethasone; } \\
\text { autologous stem } \\
\text { cell transplant with } \\
\text { melphalan; } \\
\text { observation; } \\
\text { lenalidomide, } \\
\text { dexamethasone } \\
\end{array}$ \\
\hline & $614 \mathrm{~T} 2$ & $60, F$ & MM & Relapsed & 5-10 & $\begin{array}{l}\text { Hyperdiploid, } \mathrm{t}(11 ; 14)+, \\
13 \mathrm{q}^{-}, 1 \mathrm{q}^{+}\end{array}$ & 4 & $\begin{array}{l}\text { Cyclophosphamide } \\
\text {, bortezomib, } \\
\text { dexamethasone; } \\
\text { carfilzomib, } \\
\text { lenalidomide, } \\
\text { dexamethasone; } \\
\text { autologous stem } \\
\text { cell transplant with } \\
\text { melphalan; } \\
\text { bortezomib, } \\
\text { lenalidomide, } \\
\text { dexamethasone; } \\
\text { elotuzumab, } \\
\text { lenalidomide, } \\
\text { bortezomib, } \\
\text { dexamethasone; } \\
\text { pomalidomide } \\
\text { dexamethasone }\end{array}$ \\
\hline & 1070 & $65, \mathrm{~F}$ & MM & Relapsed & 20 & $\mathrm{t}(11 ; 14)+, 17 \mathrm{p}-$ & 4 & $\begin{array}{c}\text { Cyclophosphamide } \\
\text {, bortezomib, } \\
\text { dexamethasone; } \\
\text { carfilzomib, } \\
\text { lenalidomide, } \\
\text { dexamethasone; } \\
\text { pomalidomide, } \\
\text { dexamethasone; } \\
\text { daratumumab }\end{array}$ \\
\hline \multirow[t]{5}{*}{ EU } & 101711 & $56, F$ & $\begin{array}{c}\text { Primary } \\
\text { Plasma Cell } \\
\text { Leukemia }\end{array}$ & Diagnosis & 83 & Hyperdiplpoid & 0 & None \\
\hline & 051719 & $66, F$ & $\underset{\text { pleural effusion }}{\text { MM }}$ & Relapsed & 38 & $\begin{array}{c}\mathrm{t}(4 ; 14)-\text { del17+ } \\
\text { CCND1-;ITGB7-; FRZB- }\end{array}$ & 2 & $\begin{array}{l}\text { Bortezomib; } \\
\text { lenalidomide }\end{array}$ \\
\hline & 051720 & $70, F$ & $\begin{array}{l}\text { Secondary } \\
\text { Plasma Cell } \\
\text { Leukemia }\end{array}$ & Relapsed & 25 & $\begin{array}{l}\mathrm{t}(4 ; 14) ; \text { del17- } \\
\text { CCND1+ }\end{array}$ & 3 & $\begin{array}{l}\text { Bortezomib; } \\
\text { lenalidomide; } \\
\text { pomalidomide }\end{array}$ \\
\hline & 071739 & $62, \mathrm{M}$ & MM & Relapsed & 70 & $\begin{array}{c}\mathrm{t}(4 ; 14)-; \text { del } 17- \\
\text { FRZB }+\end{array}$ & 2 & $\begin{array}{l}\text { Bortezomib; } \\
\text { lenalidomide }\end{array}$ \\
\hline & MM49 & $66, \mathrm{M}$ & $\begin{array}{l}\text { Secondary } \\
\text { Plasma Cell } \\
\text { Leukemia }\end{array}$ & Relapsed & 44 & $\begin{array}{c}\mathrm{t}(4 ; 14)-\mathrm{t}(11 ; 14) ; \text { del17+ } \\
\text { ITGB7+ }\end{array}$ & 4 & $\begin{array}{l}\text { Bortezomib; } \\
\text { lenalidomide; } \\
\text { pomalidomide; } \\
\text { bendamustine }\end{array}$ \\
\hline
\end{tabular}

Fig. S5. (A) Demographic, cytogenetic and treatment characteristics of bone marrow or 
peripheral blood samples donated by MM patient cohorts in the USA and EU as depicted in Fig. 5. HD, hyperdiploid. ASCT, autologous bone marrow transplant with melphalan. 
A

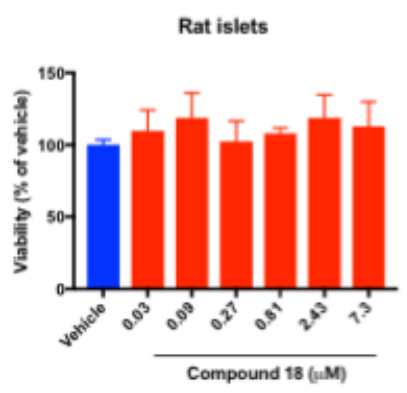

B

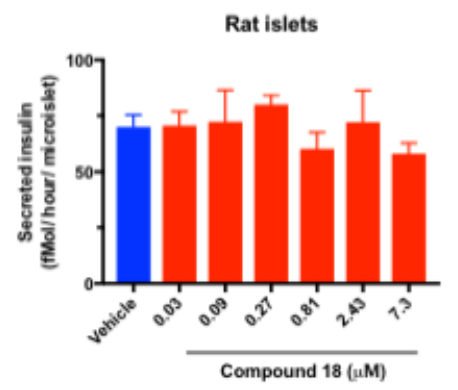

Fig. S6. IRE1 $\alpha$ kinase inhibition preserves survival and insulin secretion by pancreatic islet 3D microtissues. Rat pancreatic islets were isolated, dissociated into single cells, replated in microtiter wells (1000 cells/drop), and allowed to form 3D

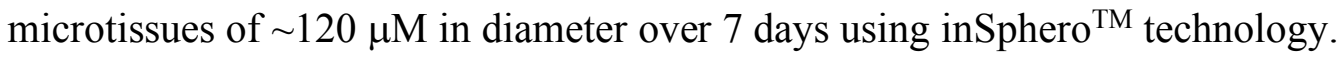
Microtissues ( $\mathrm{n}=5$ per treatment) were then incubated for 7 days in the absence or presence of compound $\mathbf{1 8}$ at the indicated concentrations, and then $(\boldsymbol{A})$ analyzed for cell viability by ATP levels; or $(\boldsymbol{B})$ challenged with glucose $(16.7 \mathrm{mM})$ for $1 \mathrm{hr}$ and analyzed for insulin secretion by ELISA. 


\section{References}

1. Mali P, et al. (2013) RNA-guided human genome engineering via Cas9. Science 339(6121):823-826.

2. Callow MG, et al. (2018) CRISPR whole-genome screening identifies new necroptosis regulators and RIPK1 alternative splicing. Cell Death Dis 9(3):261.

3. Chang TK, et al. (2018) Coordination between Two Branches of the Unfolded Protein Response Determines Apoptotic Cell Fate. Mol Cell 71(4):629-636 e625.

4. Pinheiro J, Bornkamp B, Glimm E, \& Bretz F (2014) Model-based dose finding under model uncertainty using general parametric models. Stat Med 33(10):16461661.

5. Korennykh AV, et al. (2009) The unfolded protein response signals through highorder assembly of Ire1. Nature 457(7230):687-693. 